\title{
Apoptotic CD8 T-lymphocytes disable macrophage-mediated immunity to Trypanosoma cruzi infection
}

\author{
MP Cabral-Piccin ${ }^{1,3}$, LVC Guillermo ${ }^{1,3,4}$, NS Vellozo ${ }^{1,3}$, AA Filardy ${ }^{1}$, ST Pereira-Marques ${ }^{1}$, TS Rigoni ${ }^{1}$, WF Pereira-Manfro ${ }^{1,5}$, \\ GA DosReis ${ }^{1,2}$ and MF Lopes ${ }^{*, 1}$
}

Chagas disease is caused by infection with the protozoan Trypanosoma cruzi. CD8 T-lymphocytes help to control infection, but apoptosis of CD8 T cells disrupts immunity and efferocytosis can enhance parasite infection within macrophages. Here, we investigate how apoptosis of activated CD8 T cells affects M1 and M2 macrophage phenotypes. First, we found that CD8 T-lymphocytes and inflammatory monocytes/macrophages infiltrate peritoneum during acute $T$. cruzi infection. We show that treatment with anti-Fas ligand (FasL) prevents lymphocyte apoptosis, upregulates type-1 responses to parasite antigens, and reduces infection in macrophages cocultured with activated CD8 T cells. Anti-FasL skews mixed M1/M2 macrophage profiles into polarized M1 phenotype, both in vitro and following injection in infected mice. Moreover, inhibition of T-cell apoptosis induces a broad reprogramming of cytokine responses and improves macrophage-mediated immunity to $T$. cruzi. The results indicate that disposal of apoptotic CD8 T cells increases M2-macrophage differentiation and contributes to parasite persistence.

Cell Death and Disease (2016) 7, e2232; doi:10.1038/cddis.2016.135; published online 19 May 2016

Chagas disease, caused by the pathogenic protozoan Trypanosoma cruzi, is endemic in Latin America, despite efforts to control insect vector and transmission. ${ }^{1}$ T. cruzi parasites infect virtually any cell, reaching the cytoplasm, where replication ensues, followed by cell death and spread of infective parasites. Most patients remain asymptomatic, but persistence of parasites often results in chronic disease, affecting the peripheral nervous system or the heart of patients. $^{2,3}$ Cellular and humoral immune responses overcome acute infection, but fail to eliminate T. cruzi and infected cells. ${ }^{4}$ No vaccine or effective drug for treating established disease is available. ${ }^{3}$

The protozoan T. cruzi is equipped with a molecular apparatus that triggers multiple Toll-like receptors and induces innate immunity. In particular, macrophages have a critical role as host cells, antigen-presenting cells, and effectors for parasite killing. ${ }^{5-8}$ Depending on stimuli, macrophages can express distinct activation phenotypes and effects on infection. M1/classically activated/M (LPS+IFN- $\gamma$ ) macrophages usually produce IL-12 and NO for killing of intracellular pathogens, whereas alternatively activated macrophages, belonging to the M2 spectrum, help tissue repair and actually promote infection and tumor growth. ${ }^{9-12}$

$\mathrm{T}$ cells as well as antibodies are required to control infection. ${ }^{13-15}$ CD8 T cells eliminate cells harboring parasites in the cytoplasm, whereas both CD4 and CD8 T cells produce IFN- $\gamma$ and activate macrophages to restrain infection. ${ }^{16,17}$ Effector T-lymphocytes also promote immunopathology in the heart. ${ }^{18,19}$ Conversely, regulatory mechanisms, provided by cytokines and apoptosis of effector cells, dampen inflammation and prevent pathology, but might contribute for parasite persistence. $^{20,21}$

Lymphocytes undergo apoptosis in the course of T. cruzi infection, negatively affecting T-cell expansion, ${ }^{22,23}$ B-cell response, ${ }^{24}$ parasite killing by classically activated macrophages, ${ }^{23,25}$ and CD8 T-cell-mediated immunity. ${ }^{26,27}$ Furthermore, uptake of apoptotic cells promotes infection within macrophages, through production of prostaglandin E-2 (PGE-2), TGF- $\beta$, and polyamines, ${ }^{28}$ features associated with M2/alternatively activated macrophages. ${ }^{9}$ By contrast, blockade of PGE-2 production or inhibition of lymphocyte apoptosis by caspase inhibitors reduces parasite growth in vitro and parasitemia. ${ }^{28,29}$ Therefore, apoptosis and efferocytosis stand as potential therapeutic targets. ${ }^{20,30,31}$ However, it remains unknown whether efferocytosis affects M1/M2 macrophage polarization under the inflammatory setting of infection.

We investigated the molecular mechanisms underlying T-cell apoptosis in T. cruzi infection and found functional expression of both Fas (CD95) and Fas ligand (FasL), ${ }^{23,26}$ caspase- 8 activity, and activation of effector caspase- $3^{29,32}$ in

\footnotetext{
${ }^{1}$ Instituto de Biofísica Carlos Chagas Filho, Centro de Ciências da Saúde, Universidade Federal do Rio de Janeiro, Avenida Carlos Chagas Filho 373, CCS-IBCCF, Ilha do Fundão, Rio de Janeiro, RJ, Brazil and ${ }^{2}$ Instituto Nacional para Pesquisa Translacional em Saúde e Ambiente na Região Amazônica, Conselho Nacional de Desenvolvimento Científico e Tecnológico/MCT, Rio de Janeiro, RJ, Brazil

*Corresponding author: MF Lopes, Instituto de Biofísica Carlos Chagas Filho, Centro de Ciências da Saúde, Universidade Federal do Rio de Janeiro, Avenida Carlos Chagas Filho 373, CCS-IBCCF, Ilha do Fundão, Rio de Janeiro, RJ 21941-902, Brazil. Tel: +55 213938 6522; Fax: +55 2122808193 ; E-mail: marcelal @ biof.ufrj.br

${ }^{3}$ These authors contributed equally to this work.

${ }^{4}$ Current address: Instituto Biomédico, UNIRIO, Rio de Janeiro, RJ, Brazil.

${ }^{5}$ Current address: Faculdade de Ciências Médicas, UERJ, Rio de Janeiro, RJ, Brazil.

Abbreviations: Dpi, days post infection; FasL, Fas ligand; MGL1, macrophage galactose-type lectin-1; PEC, peritoneal exudate cell; PMA, phorbol myristate acetate; PGE-2, prostaglandin E-2

Received 18.1.16; revised 07.4.16; accepted 15.4.16; Edited by H-U Simon
} 
T cells from T. cruzi-infected mice. To prevent apoptosis during acute infection, we used both pharmacological approaches and apoptosis-defective mouse models. ${ }^{23,26,29,32}$ However, intrinsic defects of immune responses have precluded accurate interpretations of immune outcomes in FasL-mutant mice ${ }^{23}$ or in mice expressing the caspase-8 inhibitor viral-FLIP (viral FLICE/caspase-8 inhibitory protein) in $\mathrm{T}$ cells. ${ }^{32}$ So far, the general caspase inhibitor zVAD and the antagonist anti-FasL $\mathrm{mAb}$ effectively inhibited apoptosis and potentiated immunity to $T$. cruzi infection. ${ }^{26,29}$ CD8, but not CD4, T cells seem to be preferential targets for early effects of apoptosis inhibition in acute infection, based on the earlier kinetics of CD8 T-cell activation and higher Fas expression. ${ }^{26,29}$ Both treatments improved CD8 T-cell survival, macrophage activation, and parasite control in infected mice. ${ }^{26,29}$ The interactions between CD8 T cells and macrophages have not been fully explored and might be crucial to explain effective immunity induced by inhibition of apoptosis. Moreover, it is worth investigating how activated and apoptotic CD8 T cells affect distinct phenotypes of macrophages during infection. By using primary cultures of CD8 T cells and macrophages from infected mice, we recapitulated most features observed in vivo upon inhibition of apoptosis. As assessed by in vitro and in vivo approaches, inhibition of T-cell apoptosis affects the outcome of CD8 T-cell-macrophage crosstalk to reprogram the immune response to $T$. cruzi infection.

\section{Results}

CD8 $\mathrm{T}$ cells and monocytes repopulate peritoneal cavity in $T$. cruzi infection. We used BALB/c mice infected with chemically derived metacyclic trypomastigotes of the Dm28c T. cruzi clone, as a validated experimental model of Chagas disease. ${ }^{33}$ Parasitemia peaks $\sim 3$ weeks after infection and immune responses and inflammation in the heart reproduce features of $T$. cruzi infection induced by insect-derived metacyclic parasites. ${ }^{33}$ In addition, CD8 T cells predominate in heart inflammation, ${ }^{33}$ as observed in human patients. ${ }^{34} \mathrm{We}$ assessed the phenotype of peritoneal exudate cells (PECs) during acute infection and found that about $20-40 \%$ of PECs are CD8 T cells (Figure 1a), whereas $\mathrm{CD}^{+}$cells represent only $5 \%$ of PECs in both normal and infected mice (not shown). Absolute numbers of CD8 T cells also increase during infection (Figure 1b). CD8 T cells represent an important source of IFN- $\gamma$, as detected in peritoneal exudates from infected mice (Figure 1c) and in PECs stimulated with a T. cruzi antigen (Ag; Tzelepis et al. ${ }^{35}$ ) (Supplementary Figure S1). Although $30-50 \%$ of PECs from normal mice express the F4/80 macrophage marker at high levels, only $10-20 \%$ of PECs from infected mice express $F 4 / 80$ at intermediate levels $\left(\mathrm{F} 4 / 80^{\mathrm{int}}\right.$ ) (Figure 1a). By contrast, 30$40 \%$ of PECs from infected, but not normal, mice bear the Ly6C marker of inflammatory monocytes/macrophages (Figure 1a). Absolute numbers of monocytes (Figure 1b), but not $\mathrm{F} 4 / 80^{+}$macrophages (not shown), also increase upon infection. F4/80 int macrophages from infected mice seem to be derived from $\mathrm{Ly}_{6 \mathrm{C}} \mathrm{C}^{+}$monocytes, instead of residual resident macrophages. Therefore, inflammatory monocytes/ macrophages comprise about $40-60 \%$ of PECs, which adhere to culture plates and acquire F4/80int (Figure 2d). About $90 \%$ of adherent cells are $\mathrm{F} 4 / 80^{\mathrm{int}}$ and CD $11 \mathrm{~b}$-double positive macrophages.

Macrophages from infected mice express M1 and M2 phenotypes. To address the functional phenotype of macrophages, we measured the expression of $\mathrm{IL}-12 \mathrm{p} 35$ and macrophage galactose-type lectin-1 (MGL1, CD301a) ${ }^{36}$ as surrogate M1 and M2 markers. Although most macrophages from normal mice express MGL1, IL-12p35 and MGL1 defined two subsets in macrophages from infected mice (Figure 1d). In addition, macrophages from normal mice are more permissive to parasite infection than macrophages from infected mice (Figure 1f). Interestingly, we detected $\mathrm{MGL}^{+}$macrophages associated with cell debris from apoptotic CD8 $\mathrm{T}$ cells in PECs from infected mice (Figure 1e and Supplementary Figure S2). Accordingly, $20-30 \%$ of peritoneal CD8 T cells undergo apoptosis during acute infection (not shown) and up to $40 \%$ of $\mathrm{F} 4 / 80$ macrophages bear intracellular $\mathrm{CD}^{+}$events (Supplementary Figure S2). These results suggest that the development of functional phenotypes by macrophages is under the influence of activation by type-1 cytokines versus suppression by apoptotic cells.

Blockade of FasL affects the crosstalk between $T$ cells and macrophages. We took advantage of the presence of both CD8 $\mathrm{T}$ cells and monocytes/macrophages in the peritoneum of infected mice to investigate the interactions between CD8 T cells and macrophages. We hypothesized that the presence of apoptotic cells could counterbalance macrophage activation and affect immunity to $T$. cruzi infection. We previously reported that efferocytosis enhances parasite growth within macrophages from $T$. cruzi-infected mice. ${ }^{28}$ To evaluate how apoptosis of activated $T$ cells affects macrophage phenotype, we treated cultures with the neutralizing anti-FasL or control IgG mAb (Figure 2a). Anti-FasL increased NO responses, but did not improve macrophage viability (Figure $2 \mathrm{~b}$ and Supplementary Figure S3). We also used plate-bound anti-CD8 to obtain CD8 T-cell enriched PECs from infected mice (70-80\% from culture supernatants). Strikingly, treatment with anti-FasL induced NO in CD8 T-cell enriched cultures, both in the presence and absence of $\mathrm{Ag}$ stimulation (Figure 2b, lower panels). Anti-FasL potentiated IL-12 and TNF- $\alpha$, but not IFN- $\gamma$ response in CD8 T-cell enriched cultures (Figure 2c). Treatment with anti-FasL also increased production of $\mathrm{NO}$ (Figure 2b) and of type-1 cytokines (Figure 2c) in anti-CD3activated cultures. Finally, anti-FasL reduced MGL1 expression in $\mathrm{F} 4 / 80^{+}$macrophages (Figures $2 \mathrm{~d}$ and e). Therefore, treatment of primary cultures of peritoneal lymphocytes and macrophages with anti-FasL promoted M1-macrophage phenotype, but restrained M2-macrophages.

Apoptosis in cocultured CD8 T cells disables macrophagemediated immunity. We investigated whether or not T-cell apoptosis affects macrophage activation, by coculturing macrophages with purified/splenic CD8 T cells from infected mice (Figure 3a). For infected cocultures, PECs from infected mice were carefully washed to remove non-adherent cells 


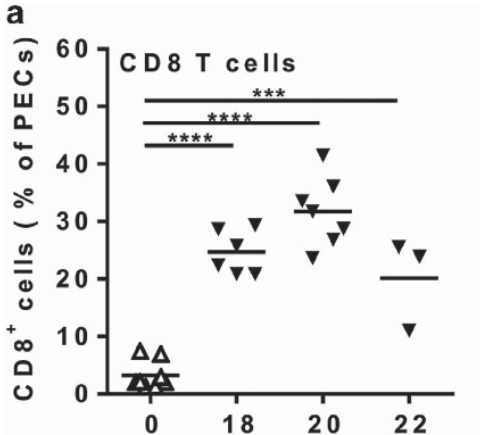

day post infection

b

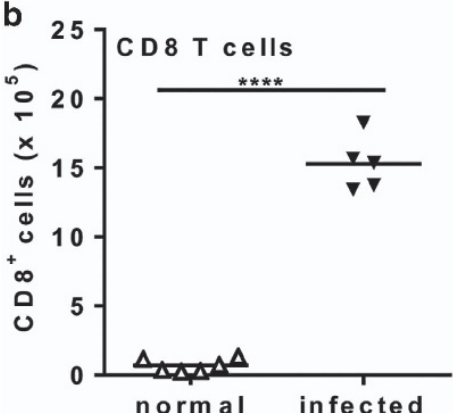

d

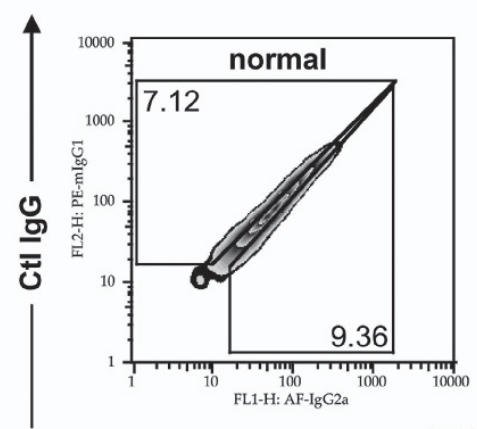

CtI lgG

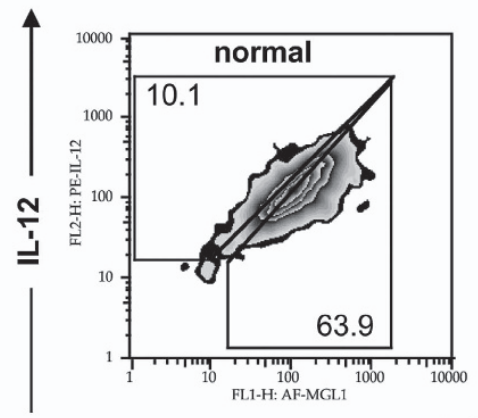

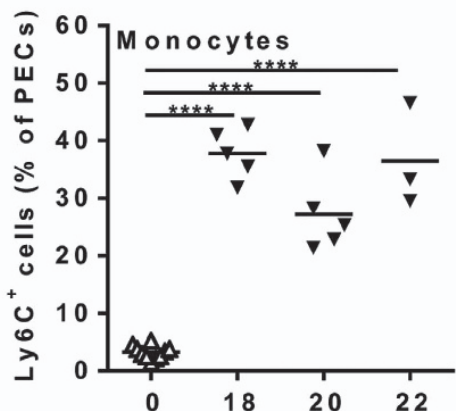

day post infection

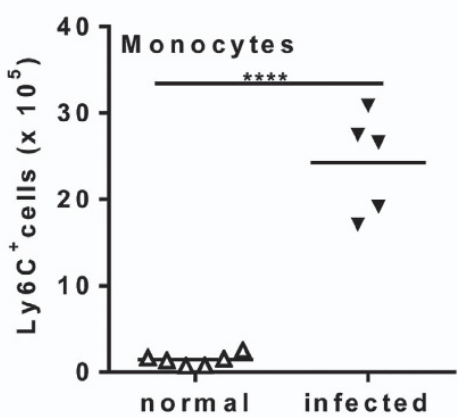

c
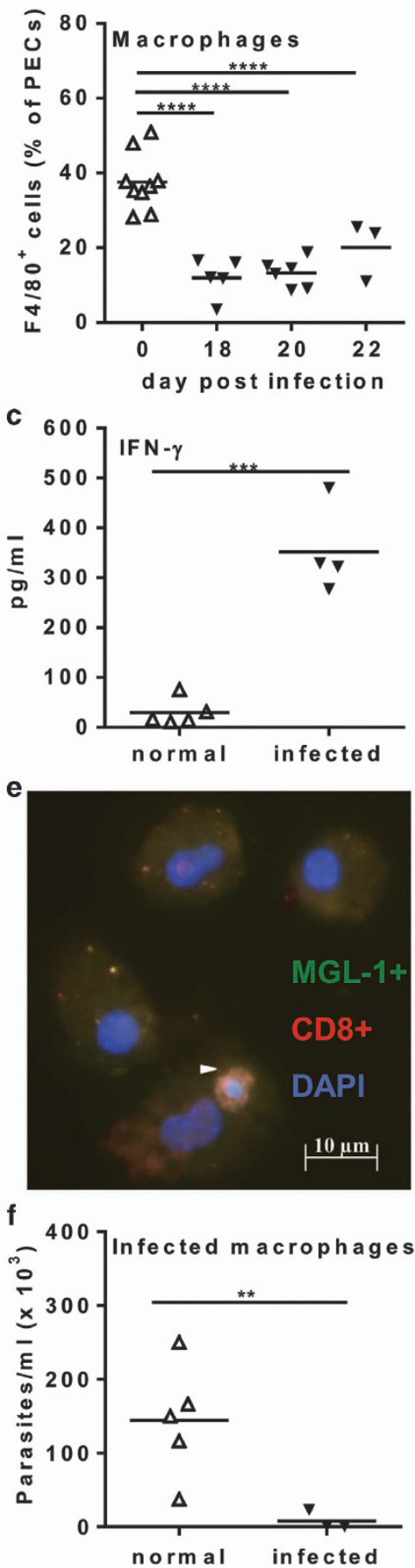

Figure 1 CD8 T cells and monocyte-derived macrophages in acute T. cruzi infection. (a) Percentages of CD8 ${ }^{+} \mathrm{T}$ cells, Ly6C $\mathrm{C}^{+}$monocytes, and F4/80 macrophages in PECs from T. cruzi-infected mice compared with PECs from uninfected (d 0) mice. (b) Absolute numbers of CD8 ${ }^{+} \mathrm{T}$ cells and $\mathrm{Ly}_{6 \mathrm{C}^{+}}$monocytes and (c) IFN- $\gamma$ in peritoneal exudates from normal and infected (18 dpi) mice. (d) Expression of MGL1 (M2) and IL-12p35 (M1) markers (as well as the respective control mAbs, upper panels) in F4/80 macrophages from normal or infected (18 dpi) mice cultured during $48 \mathrm{~h}$. (e) Image depicts PECs from infected (18 dpi) mice and represents results of three independent experiments. T cells were stained with anti-CD8 (PE, red, arrow head), macrophages stained with anti-MGL1 (Alexa Fluor 488, green), and nuclei marked with DAPI (blue). (f) Parasite burden as trypomastigotes released by macrophages from normal or infected (18 dpi) mice cultured during 3 weeks after infection with metacyclic parasites. In (a, b, c, and f), each symbol represents an individual normal $(\Delta)$ or infected $(\boldsymbol{\nabla})$ mouse. Significant differences between normal $(N=5-10)$ and infected $(N=3-7)$ mice are indicated $(*)$, as analyzed by analysis of variance (ANOVA) with Dunnett's post-test (a) and $t$-test $(\mathbf{b}, \mathbf{c}$, and $\mathbf{f})$. Graphs depicted in (d) are representative of at least three independent experiments with pools of cells from infected (18 dpi) mice, cultured in two to four technical replicates. IL, interleukin 
and then infected with metacyclic trypomastigotes. We used soluble anti-CD3 to induce activation and apoptosis of CD8 $T$ cells. Anti-FasL, but not control IgG, reduced CD8
T-cell apoptosis (based on annexin $\mathrm{V}$ and 7-AAD staining), increasing by two times the recovery of viable CD8 T cells from cocultures, but not IFN- $\gamma$ production by CD8 T cells (Figure $3 b$ ). a

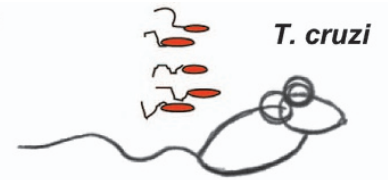

IgG

$\alpha$ FasL

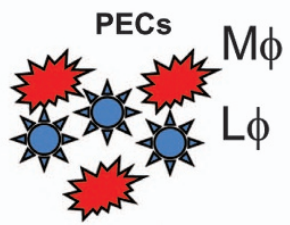

$\lg G$

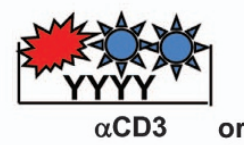

$\alpha$ FasL
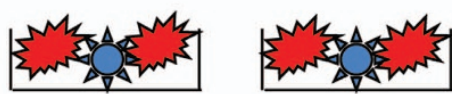

$\alpha C D 3$

b
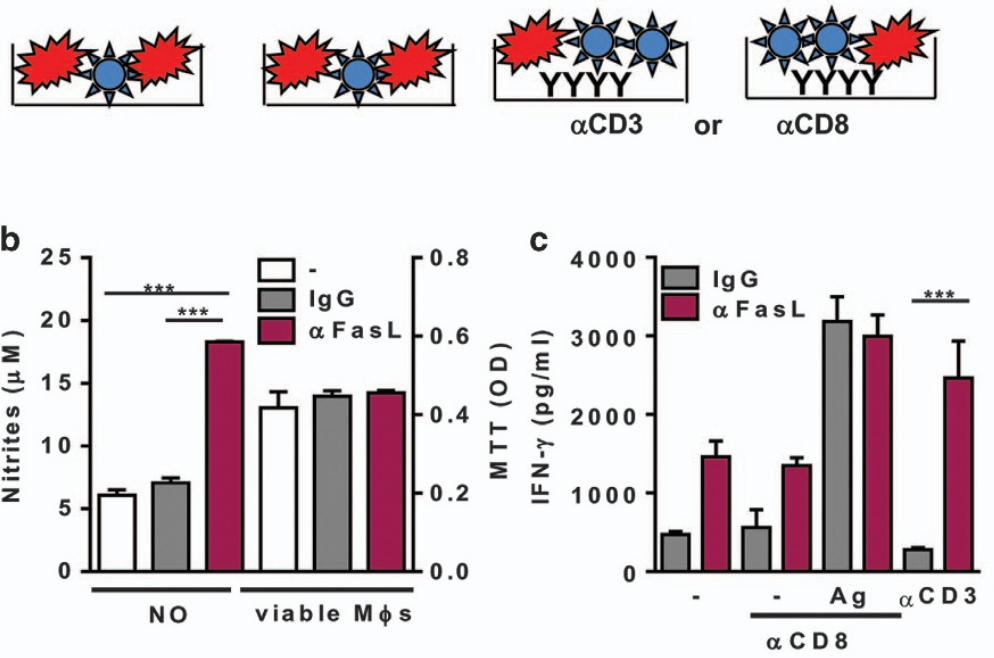

d
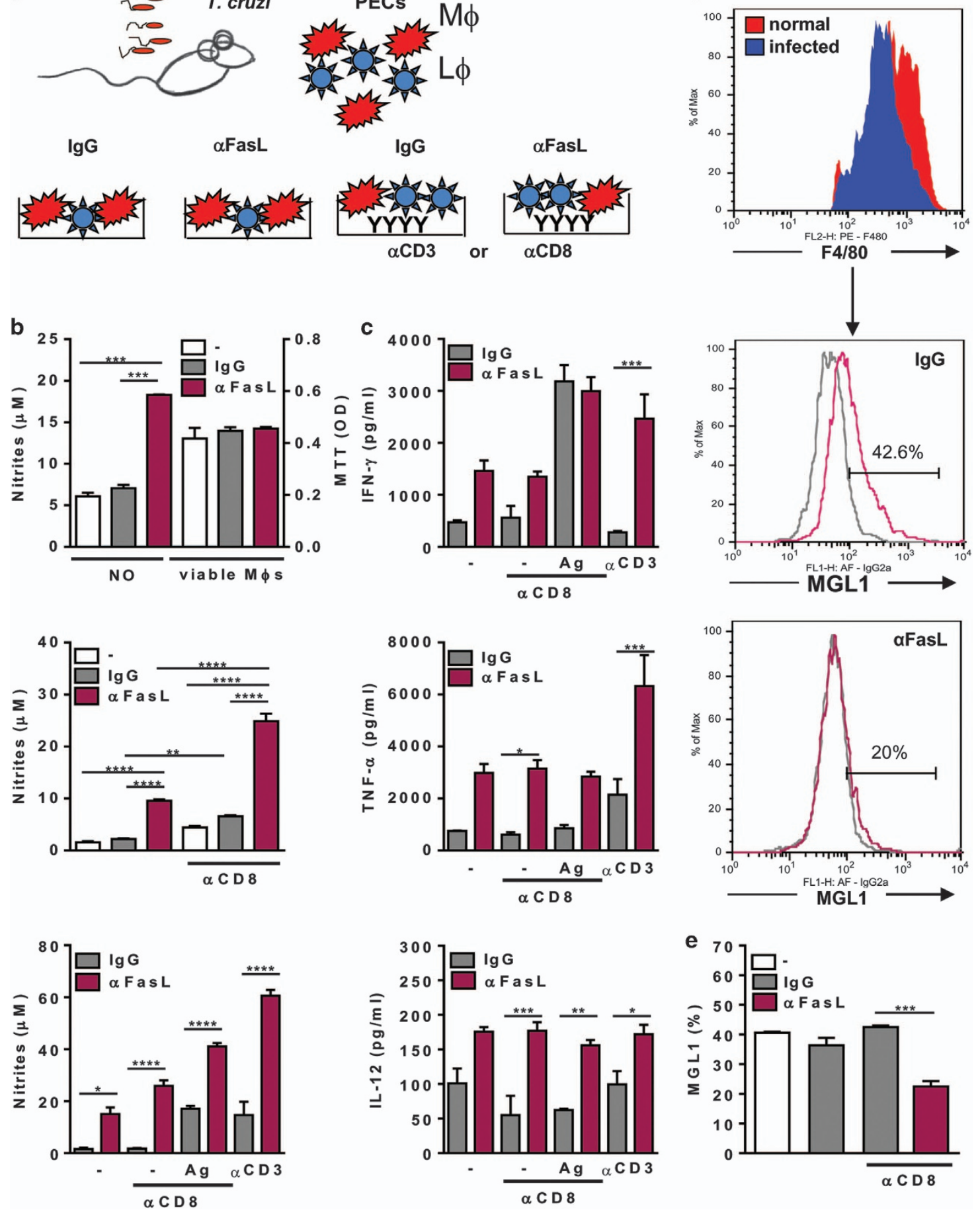

Figure 2 M2- to M1-phenotype shift in peritoneal cells treated with anti-FasL. (a-f) PECs from normal or T. cruzi-infected mice (18-20 dpi) were cultured with or without platebound anti-CD8 or anti-CD3 in the presence or absence of anti-FasL or control immunoglobulin $\mathrm{G}$ (lgG). (b and $\mathbf{c}$ ) Some cultures were stimulated with $T$. cruzi Ag, as indicated. (b) NO production in supernatants and viability of adherent cells (by MTT assay) were evaluated after $24 \mathrm{~h}$ (b, upper panel) or $48 \mathrm{~h}$. (c) secreted cytokines were measured in $48 \mathrm{~h}$ supernatants by enzyme-linked immunosorbent assay (ELISA). (d and e) Cells were detached for evaluation of MGL1 expression in gated F4/80 ${ }^{+}$cells. Results are expressed as means and S.E.M. and represent three independent experiments with three technical replicates of pooled cells from infected mice. Significant differences between treatments are indicated $\left({ }^{*}\right)$, as analyzed by $t$-test (e) or by analysis of variance (ANOVA) with Tukey's post-test (b, upper panel) or by two-way ANOVA with Tukey's (b, middle panel) or Bonferroni (b, lower panel, and c) post-test 
a PECs
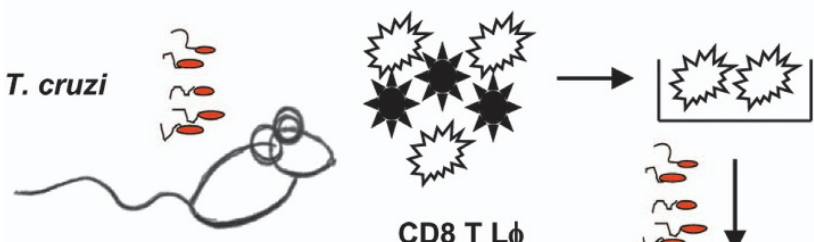

CD8 T L $\phi$
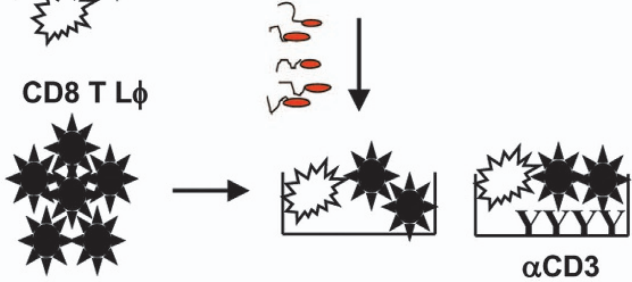

$\alpha$ FasL

$\lg G$

b
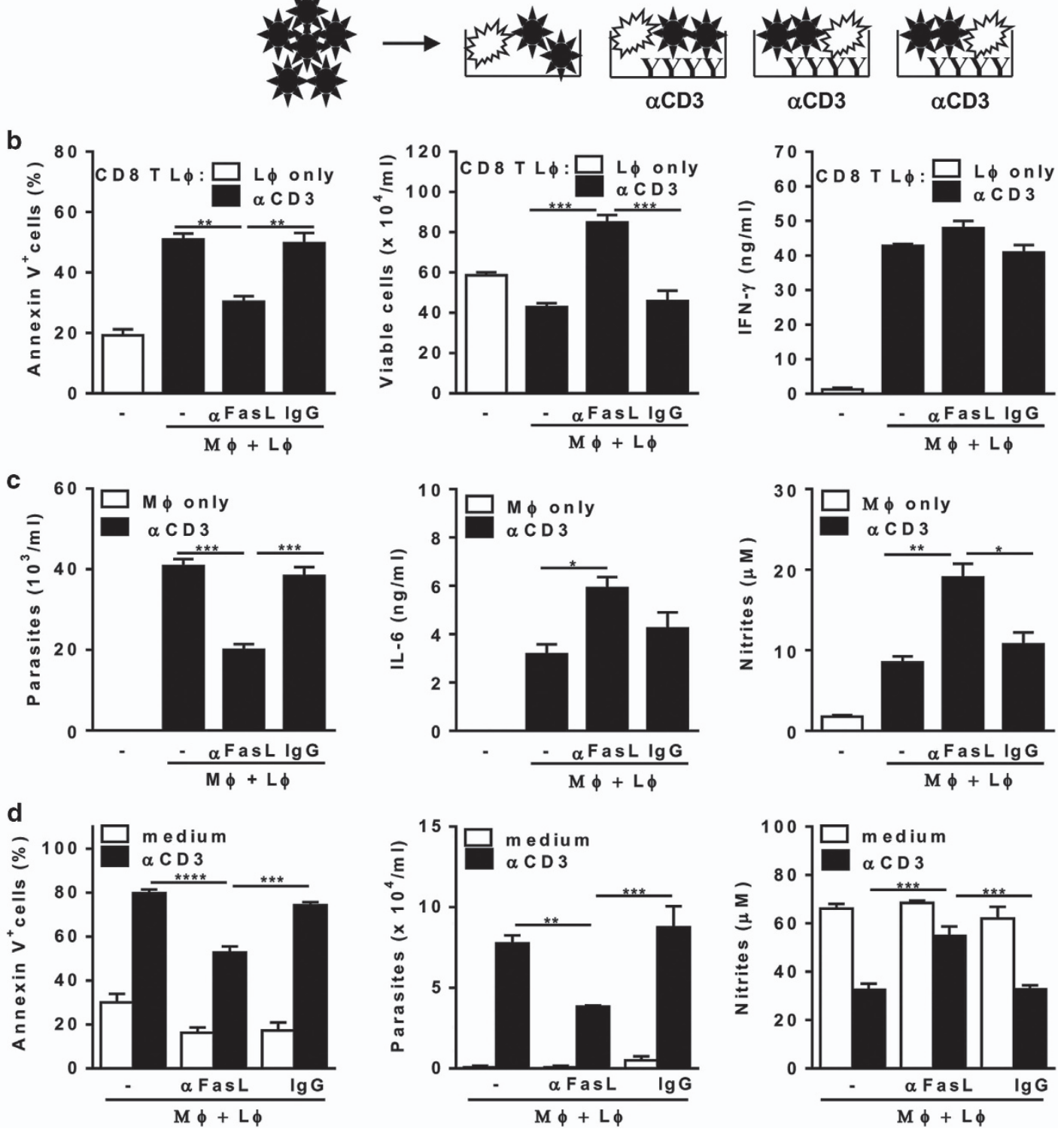

Figure 3 FasL-mediated apoptosis of CD8 T cells drives T. cruzi infection in cocultured macrophages. (a-d) Peritoneal macrophages from infected (18 dpi) mice were infected with $T$. cruzi and cocultured with purified splenic CD8 T cells from infected (18-20 dpi) mice in the presence of interleukin-2 (IL-2). Cocultures were stimulated or not with soluble anti-CD3 and treated or not with anti-FasL or control immunoglobulin $\mathrm{G}(\mathrm{lgG})$. (b-d) After $48 \mathrm{~h}$, culture supernatants were collected for NO or cytokine responses. (b and d) CD8 T cells were collected for detection of apoptosis by annexin V and 7-aminoactinomycin D (7-AAD) staining. (c and d) Adherent cells were cultured during 2-3 weeks for determination of parasite burden, as released trypomastigotes. Data are expressed as means and S.E.M. of three technical replicates. Each set of data (b-d) represents at least three independent experiments. Significant differences between treatments in anti-CD3 activated cultures are indicated $\left({ }^{*}\right)$, as analyzed by analysis of variance (ANOVA) (b and $\left.\mathbf{c}\right)$ or by two-way ANOVA (d) with Tukey's post-test

Remarkably, parasites replicated in the presence of activated CD8 T cells, as opposed to cultures with macrophages only (Figure $3 \mathrm{c}$ ), in spite of NO production in activated cocultures (Figure 3c). By contrast, treatment with anti-FasL helped macrophages to control infection and further increased macrophage activation, as assessed by IL-6 and NO production (Figure 3c). Anti-FasL did not increase IFN- $\gamma$ in cocultures and neutralization of IFN- $\gamma$ did not revert the 
effects of anti-FasL on NO production (not shown). In addition, we did not find any direct effect of anti-FasL on macrophages alone (not shown). To address any role of antiFasL independent of preventing activation-induced apoptosis, unstimulated cocultures were also treated with anti-FasL or control lgG (Figure 3d). Apoptosis in CD8 T cells and parasite growth in macrophages were observed in anti-CD3-activated cocultures, whereas concomitant treatment with anti-FasL reduced apoptosis and $T$. cruzi infection (Figure 3d, left panels). Treatment with anti-FasL also improved NO production in stimulated cocultures (Figure $3 \mathrm{~d}$ ). Compared with control IgG, we did not find any significant effect of anti-FasL in unstimulated cocultures (Figure $3 d$ ). These results are compatible with previously observed deleterious effects of efferocytosis on NO production and parasite killing induced by direct activation with IFN- $\gamma$ and LPS. ${ }^{28}$

FasL-induced T-cell apoptosis reprograms macrophage responses. The functional phenotype of infected macrophages cocultured with CD8 T cells was also assessed by cytokine array and ELISA assays. Stimulation of CD8 T cells by anti-CD3 triggered apoptosis, promoted parasite growth, reduced NO production (Figure 4a), and induced a reprogramming of macrophage phenotype (Figure $4 \mathrm{~b}$ ). In the absence of anti-CD3, cocultured (infected) macrophages expressed a predominant M1 phenotype, by producing NO (Figure 4a) as well as type-1 cytokines (Figure 4b, upper and lower panels). We were able to identify at least two distinct patterns of responses to activation with anti-CD3 and treatment with anti-FasL. First, anti-CD3 downmodulated NO and M1 cytokines (Figures $4 a$ and b, lower panels). Second, a new set of cytokines (IL-1 $\beta$, IL-3, IL-10, IL-13, and GM-CSF) was upregulated (Figure 4b). Remarkably, treatment with anti-FasL prevented activation-induced apoptosis, reduced parasite growth, and partially restored NO production as well as the M1 phenotype (Figures $4 \mathrm{a}$ and b, lower panels). By contrast, IL-3, IL-13, and GM-CSF were downmodulated upon anti-FasL treatment (Figure 4b). Only low levels of other type-1 (IL-12p70, IL-23) or type-2 (CCL11, CCL17, IL-4, IL-5) responses were detected (not shown). To rule out the effects of parasites on cytokine responses, we further assessed treatment with anti-FasL to prevent apoptosis in cocultures that were not exposed to T. cruzi in vitro (Figure 5a). Different from infected cocultures, type-1 cytokines were at basal levels in unstimulated cocultures (Figure 5b). Nonetheless, secretion of CXCL9, TNF- $a$, and G-CSF increased upon anti-CD3 stimulation (Figure 5b). Similarly, IL-1 $\beta$, IL-3, IL-10, $\mathrm{IL}-13$, and GM-CSF were upregulated in activated cocultures. Treatment with anti-FasL reduced the levels of IL-1 $\beta$, IL-3, IL-13, and GM-CSF, but increased CXCL9 secretion (Figure 5b). Therefore, activation-induced T-cell apoptosis induces macrophages to express an M2-like phenotype that is unable to control $T$. cruzi infection.

Anti-FasL reduces $M 2$ macrophages in $T$. cruzi infection. We investigated whether treatment in vivo with anti-FasL would be effective enough to modulate macrophage phenotype in the activated setting of infection. We evaluated macrophage phenotype 3 days after a single intraperitoneal injection of anti-FasL in infected mice (Figure 6a). Compared with mice that received control IgG, mice treated with antiFasL showed increased production of G-CSF, but reduced secretion of IL-1 $\beta$, IL-3, IL-10 (Figure $6 \mathrm{~b}$ ), and expression of the M2 marker MGL1 in F4/80 $0^{+}$macrophages (Figure $6 \mathrm{~d}$ ). Moreover, spontaneous NO production increased in $24 \mathrm{~h}$ cultured macrophages, whereas parasite growth decreased in macrophages from mice treated with anti-FasL (Figure 6c). Therefore, treatment with anti-FasL replaced mixed M1/M2 cells with effector M1 macrophages in infected mice. These results indicate that the blockade of lymphocyte apoptosis by anti-FasL improves macrophage-mediated immunity, but do not rule out the inhibition of apoptosis in other cells or other possible effects of blocking FasL during infection.

Caspase inhibition increases M1/M2 macrophage ratio. We used the general caspase inhibitor zVAD.fmk to target intracellular caspases. ${ }^{29}$ Treatment with $z V A D$ reduces caspase-3 activation and apoptosis in CD8 T cells from infected mice (Silva et al. ${ }^{29}$ and data not shown). Moreover, pretreatment with zVAD prevented efferocytosis of CD8 $T$ cells by cocultured macrophages (Supplementary Figure S2). To evaluate how blockade of T-cell apoptosis affects macrophage phenotype, we used in vitro and in vivo approaches (Figures $7 \mathrm{a}$ and b). First, plate-bound anti-CD3 captured (and activated) peritoneal $T$ cells together with adherent PECs. Then, we added ZVAD or DMSO to these primary cultures of $\mathrm{T}$ cells and macrophages or to macrophage cultures (Figure 7a). Compared with control diluent (DMSO), treatment with zVAD reduced MGL1 expression and doubled the IL-12/MGL1 ratio in $\mathrm{F} 4 / 80^{+}$macrophages from activated cultures (Figure 7a). Therefore, treatment of activated cultures of peritoneal lymphocytes and macrophages with zVAD altered macrophage phenotype. We did not find significant effects of zVAD on macrophages alone. For in vivo experiments, splenic T cells (both CD4 and CD8 $T$ cells at a 1:1 ratio) from infected mice were first stimulated with anti-CD3 in the presence of ZVAD or DMSO for 4 or $24 \mathrm{~h}$ (for apoptosis assays, Figure 7c). After $4 \mathrm{~h}$, activated T cells were washed and injected in infected mice (Figures $7 d$ and e). Controls were infected mice injected with PBS. After 2 days, PECs were collected and activated, before staining for MGL1 and IL-12p35 expression in F4/80 cells. Following injection of activated $\mathrm{T}$ cells treated with $\mathrm{zVAD}, \mathrm{F} 4 / 80^{+}$ macrophages from infected mice expressed two times more IL-12p35 and increased IL-12p35/MGL1 ratio (Figures 7d and e), as well as IL-12p70 (Figure 8a), compared with mice injected with DMSO-treated T cells. Peritoneal exudates from recipients of $z V A D$-treated $T$ cells also expressed increased levels of CXCL9 (Figure 8a) and reduced secretion of M2 cytokines (Figure 8b) in comparison with infected mice injected with PBS. Furthermore, cultured macrophages from mice that received $z V A D$-treated $T$ cells produced more NO and showed better control of in vitro infection than macrophages from mice injected with PBS (Figure 8c). Therefore, T-cell apoptosis has a broad effect on macrophage functional phenotype and we were able to restore macrophagemediated immunity by using strategies that prevent T-cell apoptosis both in vitro and in vivo. 

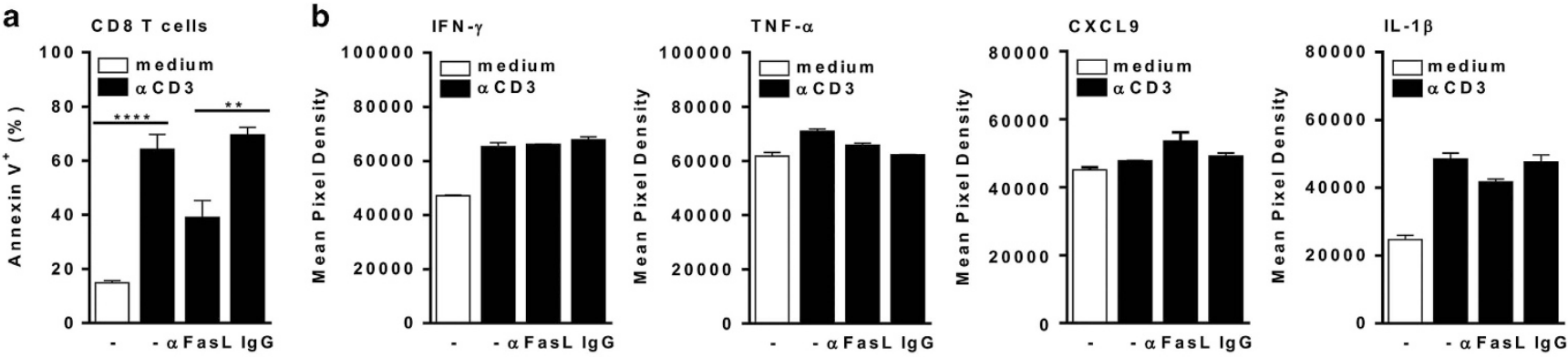

T. cruzi IL -3
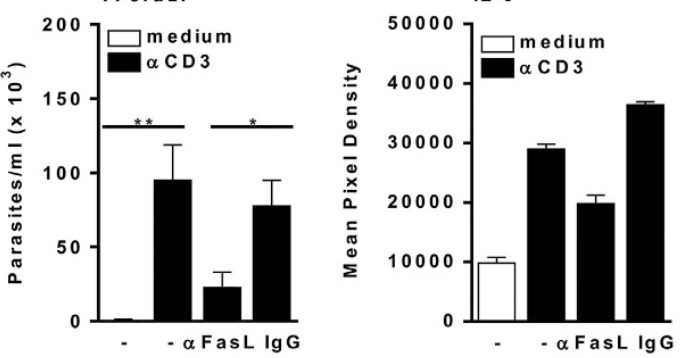

$\mathrm{IL}-10$
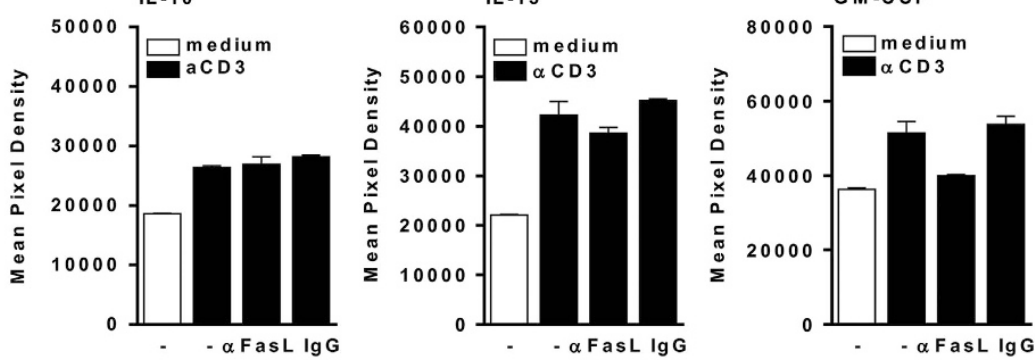

$\mathrm{NOX}$
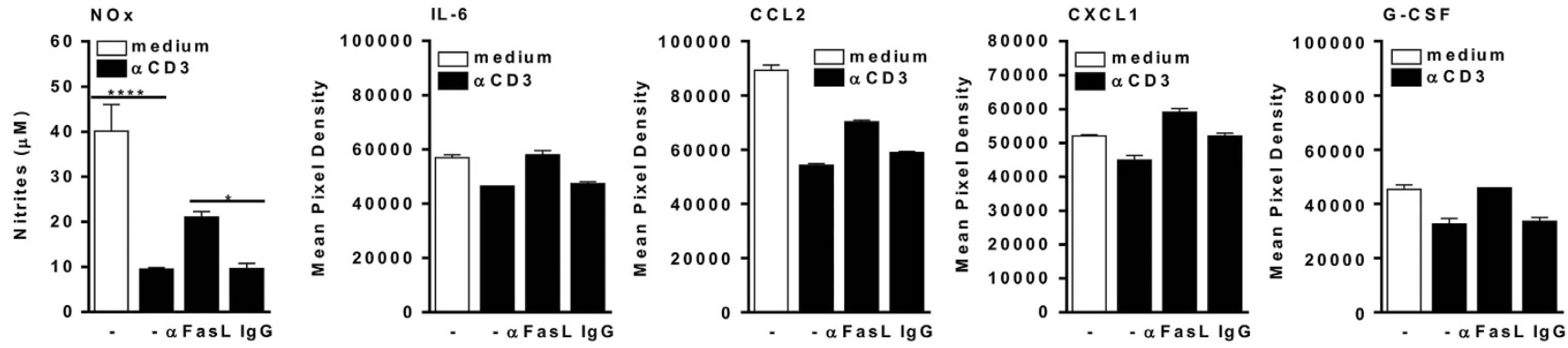

Figure 4 Apoptosis of CD8 T cells correlates with a broad reprogramming of macrophage cytokine responses. (a and $\mathbf{b})$ Infected macrophages and splenic CD8 T cells from infected mice were stimulated or not with soluble anti-CD3 in the presence of interleukin-2 (IL-2). Anti-CD3-activated cocultures were treated or not with anti-FasL or control immunoglobulin $\mathrm{G}(\mathrm{lgG})$. After $48 \mathrm{~h}$, culture supernatants were collected for evaluation of $\mathrm{NO}$ (a) or cytokine (b) responses, as assessed by a cytokine array. CD8 T cells were analyzed for annexin V/7-AAD (7-aminoactinomycin D) staining (a). Adherent cells were cultured during 4 weeks for determination of released trypomastigotes (a). Data represent mean and S.E.M. of two (b), or three to four (a) technical replicates. Data depicted in (a) represent at least three independent experiments. Significant differences between treatments are indicated $(*)$, as analyzed by analysis of variance (ANOVA) with Bonferroni post-test (a)

\section{Discussion}

Here, we addressed how the interactions between macrophages and CD8 T cells affect macrophage phenotype and ability to fight parasite infection. We found that FasL-mediated apoptosis of CD8 $\mathrm{T}$ cells induces a broad reprogramming of macrophage responses and is a promising target for upregulation of immune responses to infection. We show that interventions with agents that block T-cell apoptosis and efferocytosis (i.e., anti-FasL or zVAD) restore macrophagemediated immunity.

Previously, we used earlier and repeated injections of antiFasL or zVAD, which improved both lymphocyte and macrophage immune responses, and reduced parasitemia. ${ }^{26,29}$ Here we tested a delayed and shorter treatment during acute infection, by the timing that CD8, but not CD4, T cells reach inflammatory macrophages in peritoneal cavity. Inflammatory macrophages from infected mice express Ly6C, a monocyte marker also found in immature myeloid cells from the hearts of $T$. cruzi-infected mice. ${ }^{37}$ Therefore, during acute infection, peritoneal macrophages bear features of immature myeloid cells, and only a fraction of PECs express F4/80. Upon adherence, PECs from infected mice lose Ly6C and acquire F4/80 int expression, along with M1 (IL-12) and M2 (MGL1) markers. Nonetheless, primary cultures of macrophages and peritoneal CD8 $\mathrm{T}$ cells treated with anti-FasL or zVAD had reduced $\mathrm{M} 2$ and increased $\mathrm{M} 1$ phenotype. Moreover, cotreatment with anti-FasL exacerbated type-1 responses to both anti-CD3 and parasite Ag.

In cultures of macrophages and splenic CD8 T cells from infected mice, macrophages express NO-producing M1 phenotype and parasite killing. By contrast, activation with anti-CD3 induced apoptosis of CD8 T cells, reduced NO production, and markedly increased the number of parasites, in spite of higher levels of IFN- $\gamma$ in cocultures. Importantly, co-treatment with anti-FasL improved recovery of viable CD8 $\mathrm{T}$ cells and NO production and helped macrophages to control parasite infection. Therefore, increased parasite replication correlated with the onset of apoptosis in CD8 T cells.

Next, we focused on the cytokines modulated by both antiCD3 and anti-FasL. We found that activation and treatment with anti-FasL led to a broad reprogramming of macrophage 

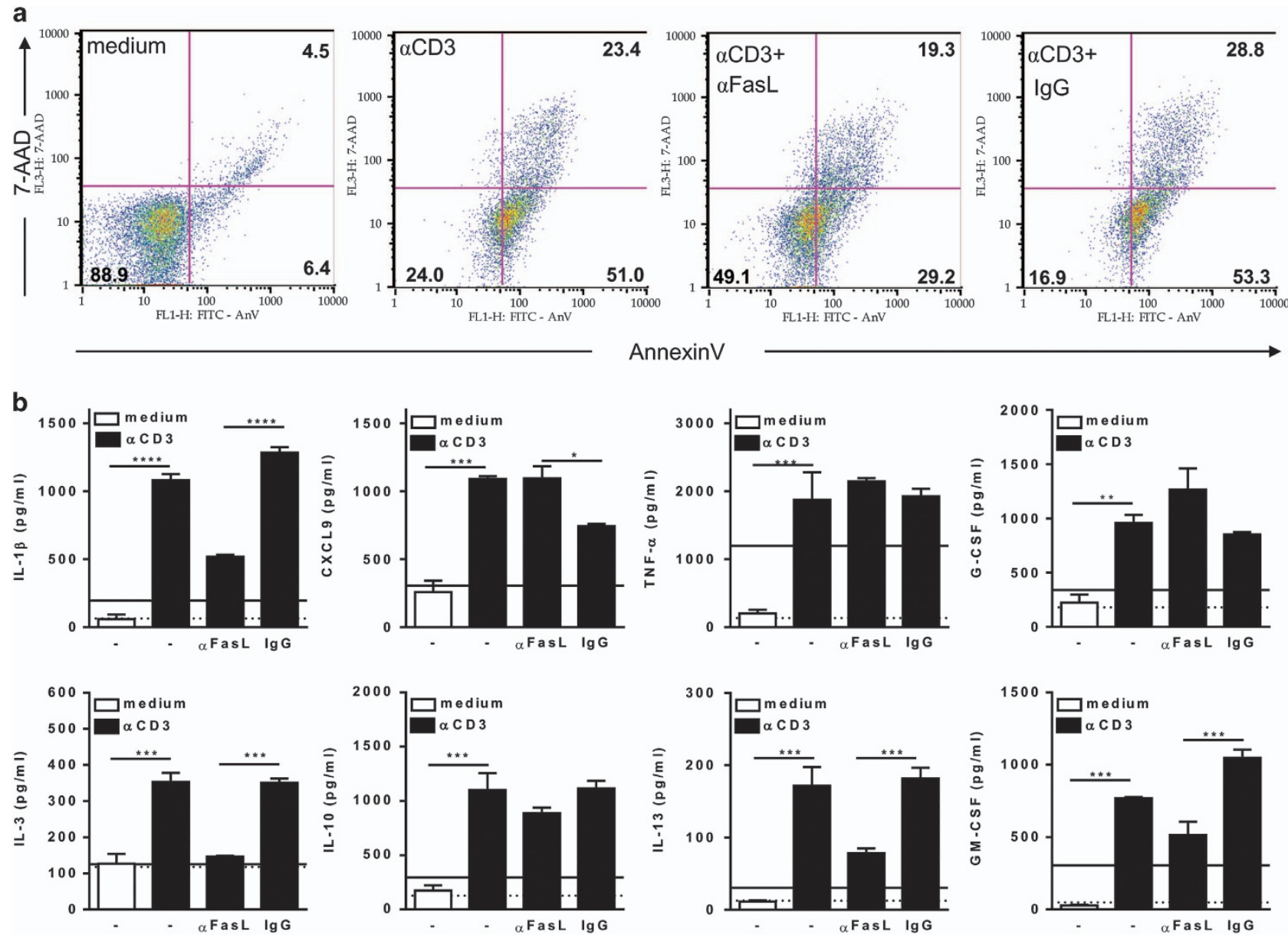

Figure 5 Apoptosis of CD8 T cells correlates with M2-cytokine responses. (a and $\mathbf{b})$ Peritoneal macrophages and splenic CD8 T cells from infected mice were stimulated or not with soluble anti-CD3 in the presence of interleukin-2 (IL-2). Anti-CD3-activated cocultures were treated or not with anti-FasL or control immunoglobulin $\mathrm{G}$ (IgG). After $48 \mathrm{~h}$, culture supernatants were collected for evaluation of cytokine responses, as assessed by enzyme-linked immunosorbent assay (ELISA) (b). CD8 T cells were analyzed for annexin V/7-AAD (7-aminoactinomycin D) staining (a). (b) Full lines stand for cytokines produced by stimulated CD8 T cells and dotted lines represent cytokine responses by macrophages. Data represents mean and S.E.M. of three to four technical replicates in at least three independent experiments. Significant differences between treatments are indicated $\left({ }^{*}\right)$, as analyzed by analysis of variance (ANOVA) with Bonferroni post-test

response. Anti-FasL upregulated the proinflammatory cytokines IL- 6 and CXCL9, but reduced IL- $1 \beta$, IL-3, IL-13, and GMCSF. Although the production of IL- $1 \beta$ might help immunity to T. cruzi, ${ }^{38} \mathrm{IL}-1 \beta$ secretion did not correlate with NO production or with parasite killing in cocultures. By contrast, parasite growth correlated with production of IL-3, IL-13 (along with IL-10), and GM-CSF, which are potential parasite promoters, either by inducing PGE-2 ${ }^{39}$ and arginase ${ }^{40}$ or by directly affecting parasite growth, ${ }^{25}$ features associated with M2 macrophages. Similarly, M2 macrophages induced in the absence of IL-12 promote infection with T. cruzi. ${ }^{10}$ Therefore, by blocking apoptosis of CD8 T cells in cocultures, treatment with anti-FasL restricted an M2-like phenotype and parasite growth and increased NO and other M1 features. Similarly, short-term treatment with anti-FasL in vivo reduced $\mathrm{M} 2$ responses, but improved parasite killing by macrophages. Therefore, the blockade of lymphocyte apoptosis with antiFasL or ZVAD correlates with upregulated M1/M2 ratio and promotes macrophage-mediated immunity. Furthermore, based on the myriad of cytokines and chemokines ${ }^{11}$ involved, it could have a broad impact on immune responses.

To our knowledge, we are the first to show that apoptosis of activated CD8 T cells directly affects the macrophage phenotype and is a potential target for improvement of immunity. Although both ZVAD and anti-FasL were effective to boost immunity, as opposed to caspase inhibition, the Fas-death pathway stands as a more selective target. This is important to prevent potential side effects of blocking apoptosis or efferocytosis, such as breaking self-tolerance and regulation of immune responses, disrupting tissue repair or affecting immunity to tumors. ${ }^{41-43}$ By contrast, treatment with anti-FasL might affect apoptosis during ongoing immune responses that lead to upregulation of FasL. Nonetheless, other direct or indirect effects of anti-FasL on macrophage activation ${ }^{44}$ or death ${ }^{45}$ could not be excluded, and potential increase of subsequent Th1 and Th2 responses ${ }^{23,26}$ should be taken into account.

Recently, Vasconcelos et al. ${ }^{27}$ showed that the proapoptotic phenotype of Ag-specific CD8 T cells expressing higher levels 
a
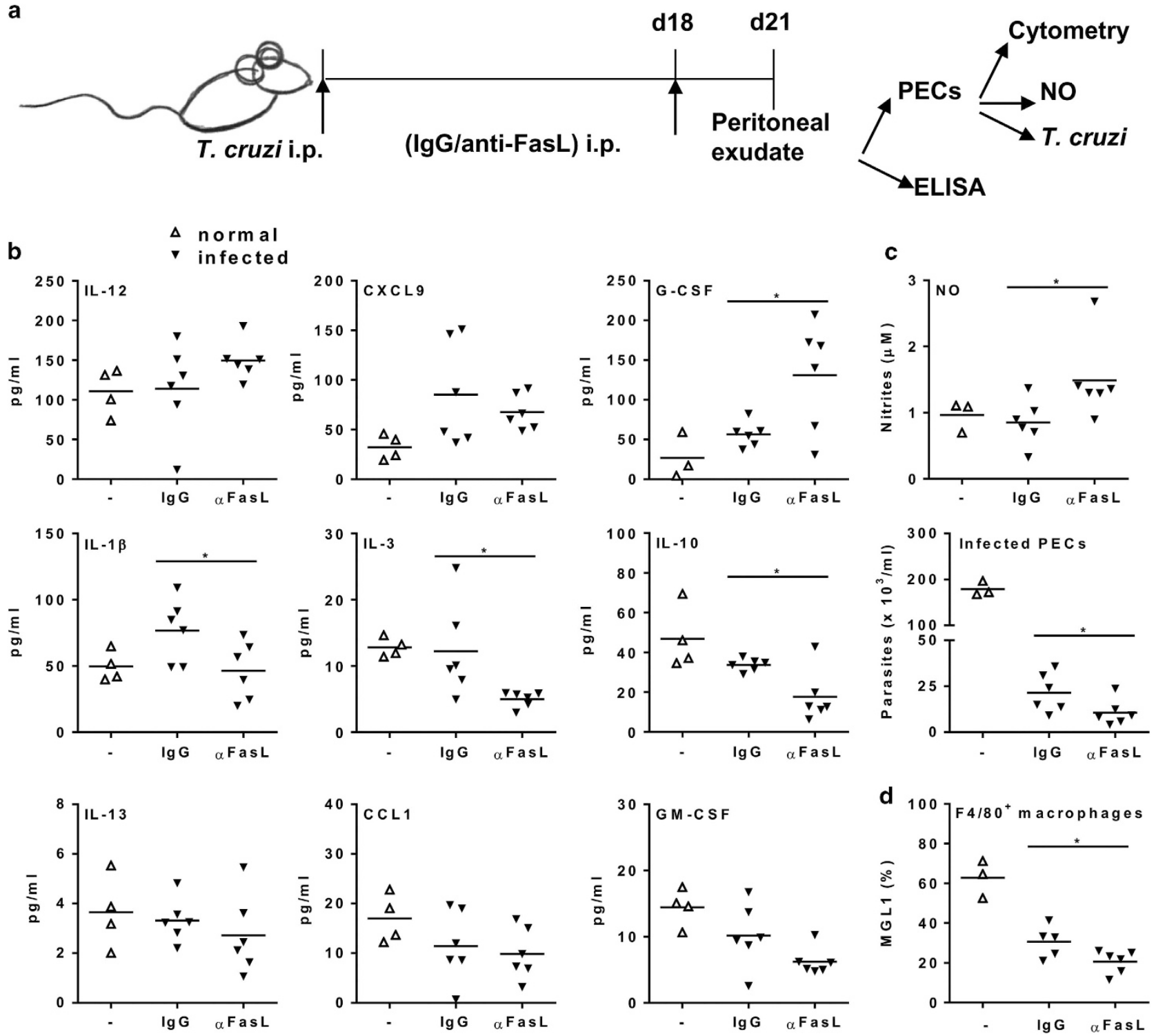

Figure 6 Treatment with anti-FasL promotes macrophage-mediated immunity to T. cruzi infection. (a-d) Infected BALB/c mice (18 dpi) were treated intraperitoneally with antiFasL $(100 \mu \mathrm{g})$ or control immunoglobulin G (lgG). Uninfected mice were used as controls. (b) After 3 days, peritoneal exudates were analyzed for cytokines and chemokines. (c) Peritoneal macrophages were cultured during $24 \mathrm{~h}$ before evaluation of spontaneous NO production or were infected with $T$. cruzi and cultured during 2 weeks before determination of parasite burden. (d) PECs were evaluated for MGL1 expression in F4/80 ${ }^{+}$cells. Symbols represent peritoneal cells or exudates from individual normal $(\Delta)$ or infected $(\nabla)$ mice treated with anti-FasL or immunoglobulin $\mathrm{G}(\mathrm{IgG})(N=6$ mice per group). In (c), each symbol represents the means of two to three technical replicates of cultured cells from each individual mouse. Significant differences between treatments are indicated as $\left(^{*}\right)$ for $P<0.05$ in $t$-test

of Fas correlates with defective immune responses to $T$. cruzi infection. Moreover, a virus vaccine expressing a parasite Ag prevented the development of proapoptotic CD8 T cells and promoted immunity, comprising both cytotoxic and cytokineexpressing CD8 $\mathrm{T}$ cells. ${ }^{27}$ Based on these and previous findings, we consider two major, but not exclusive, hypotheses to explain modulation of parasite infection by treatment with anti-FasL. First, by preventing CD8 T-cell death, antiFasL might restrain the negative effects of efferocytosis on macrophage activation. Second, anti-FasL would help immunity by rescuing effector CD8 T cells, which either activate or kill macrophages from T. cruzi-infected mice. Although we have evidence of both cytotoxic activity and IFN- $\gamma$ production by CD8
T cells, the effects of anti-FasL on macrophage phenotype do not correlate with higher IFN- $\gamma$ levels or with increased macrophage viability or with reduced cytotoxicity. It is worth investigating whether blockade of apoptosis promotes heightened effector activities by antigen-specific CD8 T cells in vivo and how treatment with anti-FasL or zVAD affects distinct subsets of effector cells. Importantly, perforin- and IFN- $\gamma$ expressing subsets of CD8 $\mathrm{T}$ cells might have opposing (pathogenic versus protective) roles in Chagas disease. ${ }^{18}$

Our results are compatible with the hypothesis that inhibition of CD8 T-cell apoptosis potentiates macrophage-mediated immunity by restraining the inhibitory effects of efferocytosis on macrophages. First, apoptotic cells have direct effects 
a
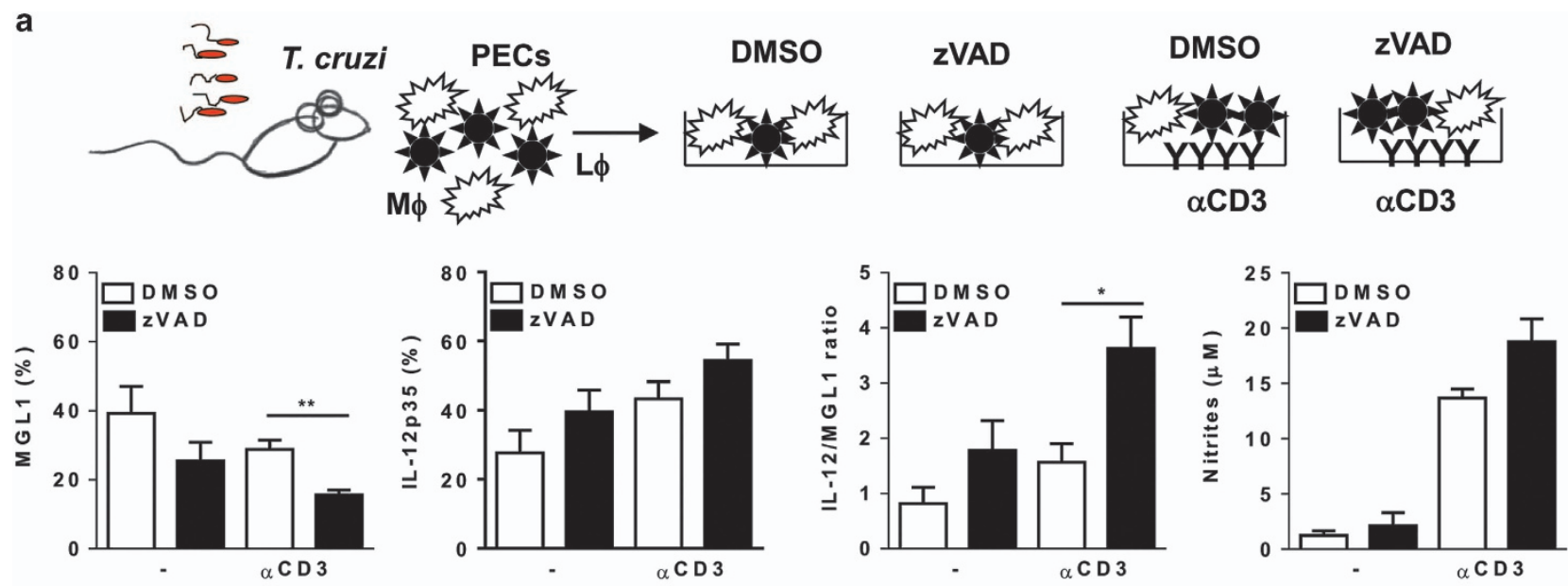

b
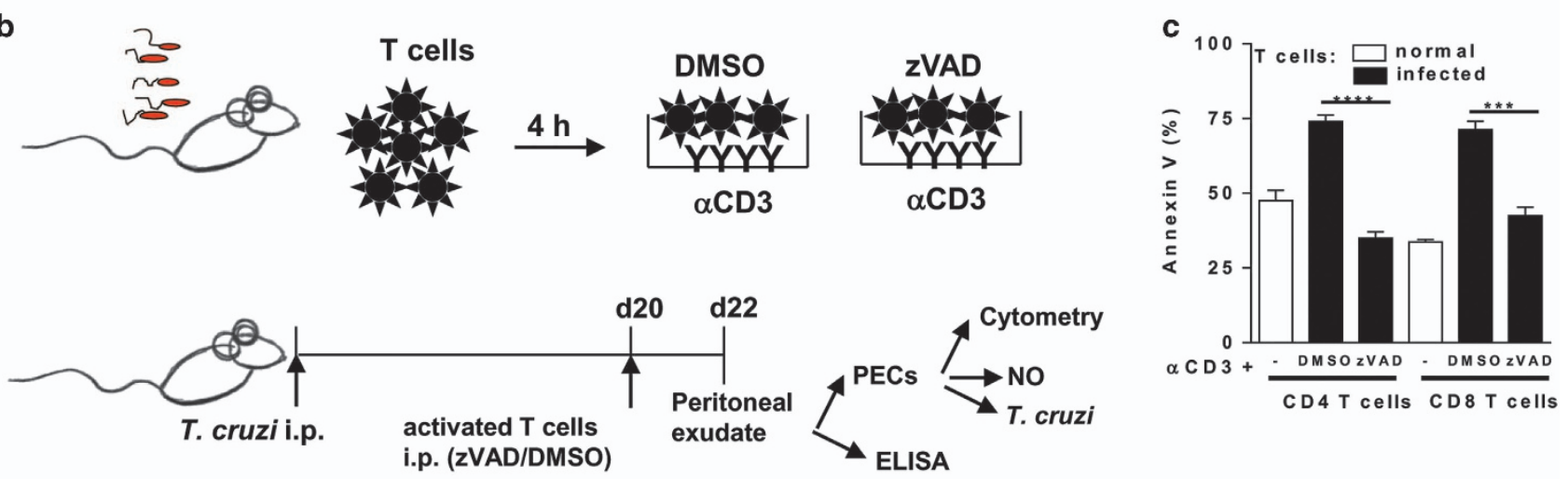

d
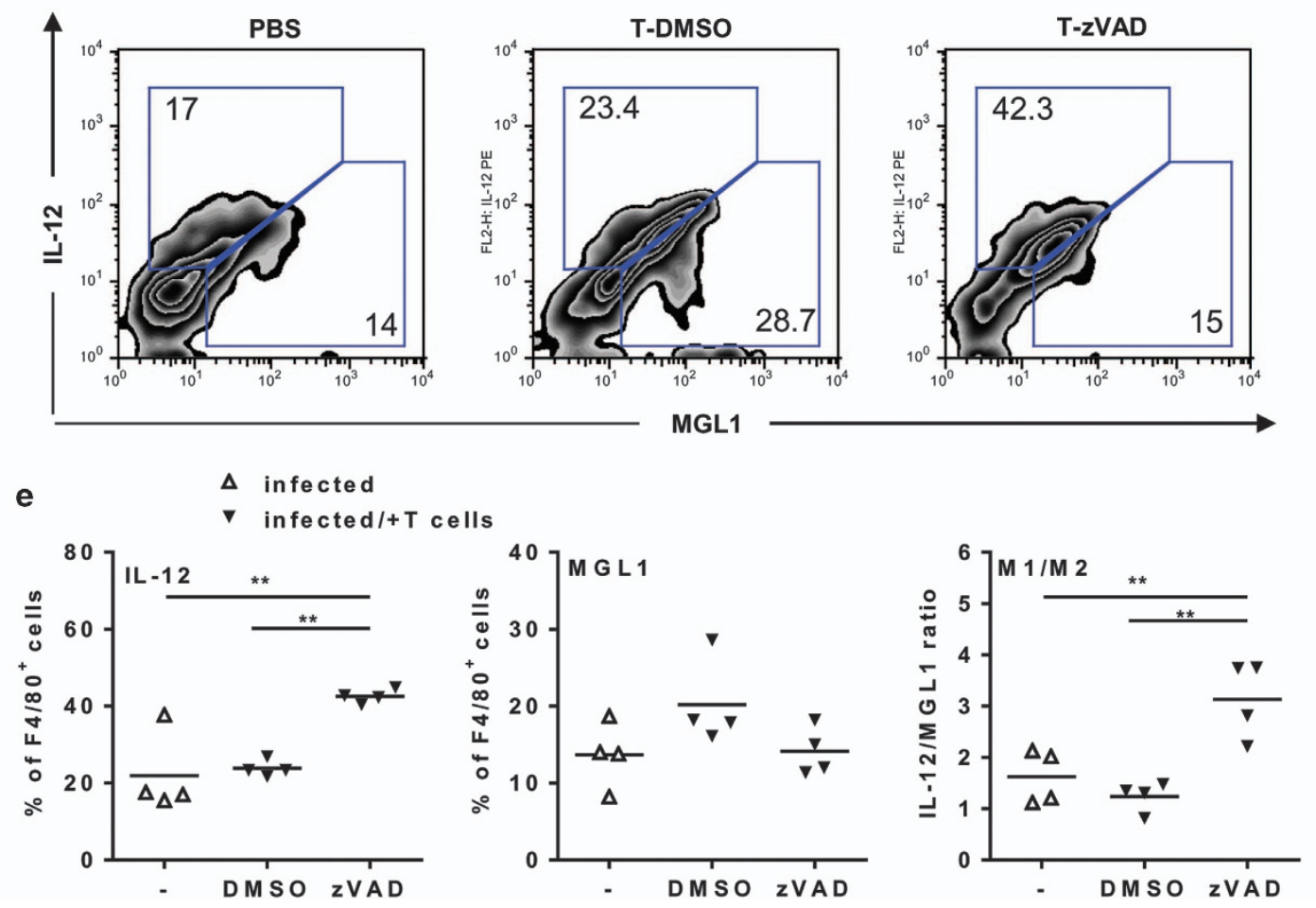
on macrophages and on infected mice to promote parasite, ${ }^{25,28,46}$ bacterial, ${ }^{47-50}$ and viral $^{51}$ infections. Second, efferocytosis changes macrophage function by inducing distinct metabolic programs ${ }^{28,50}$ and production of soluble factors. ${ }^{28,48-50}$ Efferocytosis induces secretion of TGF- $\beta,{ }^{28}$ which suppresses induced-nitric oxide synthase expression (Supplementary Figure S4) and NO production ${ }^{28}$ upon LPS and/or IFN- $\gamma$ stimulation. Third, the effects of apoptotic cells can be reverted by interfering with the uptake of apoptotic cells, the metabolic activity, or the production of soluble mediators. ${ }^{28,48,49}$ Nonetheless, it is noteworthy that either activation or suppression of immune responses ensues when efferocytosis is mediated by dendritic cells ${ }^{52,53}$ or by macrophages phagocytosing apoptotic cells, depending on the genetic background/the immune features of cells ${ }^{46}$ or infections. ${ }^{50,53,54}$ Recent findings suggest that macrophages

$\Delta$ infected

$\checkmark$ infected $+T$ cells
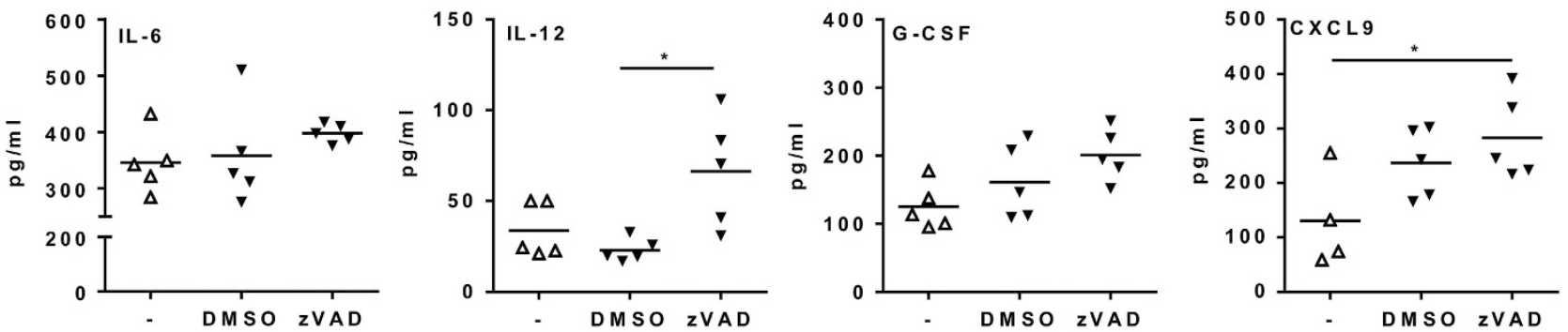

b
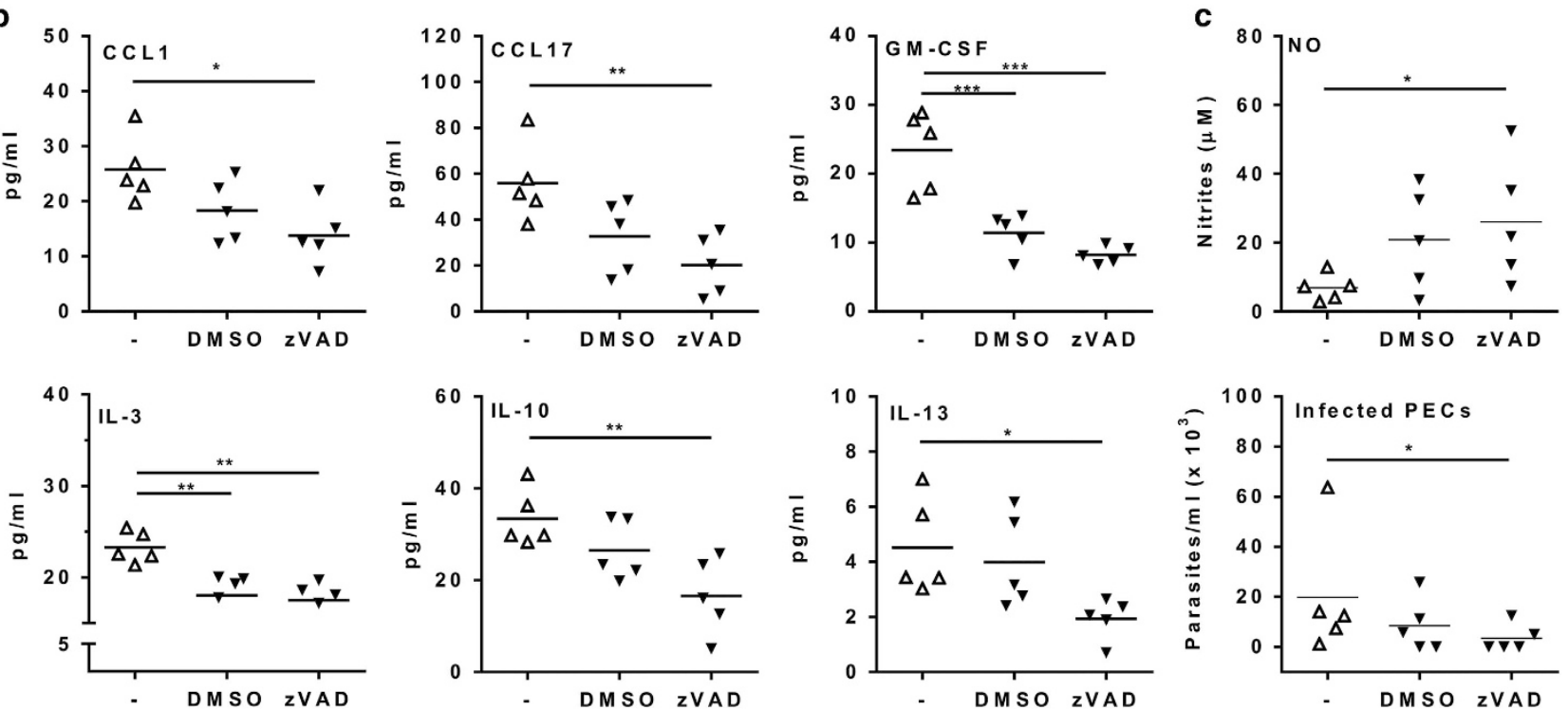

Figure 8 Inhibition of T-cell apoptosis enhances macrophage-mediated immunity to T. cruzi infection. (a-c) Splenic T cells from infected mice (18 dpi) were treated with antiCD3 in the presence of caspase inhibitor ZVAD or dimethyl sulfoxide (DMSO) for $4 \mathrm{~h}$. T cells were washed and adoptively transferred intraperitoneally to infected mice (20 dpi). Infected mice injected with phosphate-buffered saline (PBS) only were used as controls. After 2 days, peritoneal exudates were analyzed for (a) M1 and for (b) M2 cytokines. (c) Peritoneal macrophages were cultured during $24 \mathrm{~h}$ before evaluation of spontaneous NO production or infected with T. cruzi and cultured during 4 weeks before determination of parasite burden. (a and $\mathbf{b})$ Symbols represent peritoneal exudates from individual mice injected with PBS $(\Delta)$ or with activated T cells $(\boldsymbol{\nabla})$ previously treated with zVAD or DMSO ( $N=5$ mice per group). In (c), each symbol represents the mean of two to three technical replicates of cultured cells from each individual mouse. Significant differences between treatments are indicated (*), as analyzed by $t$-test (c) or by analysis of variance (ANOVA) with Tukey's post-test (a and $\mathbf{b})$

Figure 7 Inhibition of activation-induced T-cell death shifts M2 into M1 macrophages. (a) PECs from T. cruzi-infected mice were cultured with or without plate-bound anti-CD3 in the presence of caspase inhibitor zVAD or dimethyl sulfoxide (DMSO). Cells were detached after $48 \mathrm{~h}$ for evaluation of MGL1 and IL-12p35 expression in gated F4/80 ${ }^{+}$cells. NO production was measured in $48 \mathrm{~h}$ culture supernatants. Results are expressed as means and S.E.M. of three to four technical replicates of pooled PECs from infected mice. (b) T cells from normal or infected mice (20 dpi) were treated with anti-CD3 in the absence or presence of ZVAD or DMSO during $4 \mathrm{~h}$ for in vivo injection and $24 \mathrm{~h}$ (c) for flow cytometry. (c) T cells were analyzed for annexin V staining in CD8 and CD4 T cells. Results are expressed as means and S.E.M. of four to five technical replicates. (d and e) Infected mice (20 dpi) were injected intraperitoneally with phosphate-buffered saline (PBS) (-) or with $2 \times 10^{6}$ activated T cells (treated with zVAD or DMSO). After 2 days, PECs were collected and activated with PMA and ionomycin, before staining for MGL1 and IL-12p35 expression in F4/80 ${ }^{+}$cells. (e) Symbols represent PECs from individual infected mice treated with PBS $(\Delta)$ or with T cells $(\boldsymbol{\nabla})$ activated in the presence of ZVAD or DMSO ( $N=4$ mice per group). Significant differences between treatments are indicated $\left({ }^{*}\right)$, as analyzed by $t$-test (a and $\mathbf{c}$ ) or by analysis of variance (ANOVA) with Tukey's post-test (e) 
use different sets of receptors to efferocytose under homeostatic or inflammatory conditions. ${ }^{55}$ The experimental model of Chagas disease provides an opportunity to investigate how different receptors are involved in efferocytosis and modulation of macrophage phenotype under the inflammatory setting of $T$. cruzi infection as well as how this will affect the development of disease. Whereas M1 macrophages might promote inflammation, M2 macrophages can induce fibrosis in the heart ${ }^{56}$ in the context of parasite infection.

Here we show that whereas effector CD8 T cells might contribute to the inflammatory environment in tissues, apoptosis of CD8 T-lymphocytes counterbalances macrophage activation, negatively affecting immunity to $T$. cruzi infection, by promoting macrophage differentiation towards an M2-like phenotype. Moreover, pharmacologic tools that target apoptosis are able to restore M1-macrophage responses, opening new avenues to promote immunity to infectious diseases.

\begin{abstract}
Materials and Methods
Mice and $\boldsymbol{T}$. cruzi infection. BALB/c mice were obtained from the Fluminense Federal University (UFF) or from the Oswaldo Cruz Institute (FIOCRUZ) and maintained in the animal facility at the Federal University of Rio de Janeiro (UFRJ). Male BALB/c mice, aged 6-8 weeks, were infected intraperitoneally with $2 \times 10^{5}$ metacyclic trypomastigotes of Dm28c T. cruzi clone, obtained by chemically induced metacyclogenesis in triatomine artificial urine-proline medium. ${ }^{33}$ Experiments were conducted during acute (18-22 days post infection (dpi)) infection and age-matched BALB/c mice were used as uninfected controls. All procedures were approved (protocol IBCCF178) by the University's Ethical Committee for Anima Experimentation (UFRJ), according to national and institutional regulations that comprise with international standards.
\end{abstract}

Flow cytometry assays. PECs or cultured cells were washed in FACS buffer (plus $2 \%$ FCS), followed by incubation with anti-CD16/CD32 (eBioscience, San Diego, CA, USA) for Fc blocking. We stained cells with anti-CD8, anti-CD5, anti-CD19, anti-B220, anti-F4/80 mAbs, anti-CD11b, and anti-CD11c (clone HL3) labeled with PE, FITC, or allophycocyanin (BD Biosciences, Chicago, IL, USA), or with FITC-labeled anti-Ly6G (clone 1A8), allophycocyanin-labeled anti-Ly6C (clone HK1.4), or anti-CD4 mAbs (eBioscience), or with Alexa Fluor 488-labeled antiMGL1 (CD301a) mAb (AbD Serotec, Kidlington, UK) or control rat IgG2a mAb (R\&D Systems, Minneapolis, MN, USA). For intracellular staining, we washed, permeabilized, and stained cells with PE-labeled anti-IL-12p35 or control murine IgG1 mAb (R\&D Systems). For IL-12p35 (M1) and MGL1 (M2) subsets, gates were based on the exclusion of background staining with isotype control mAbs. We then washed, fixed, and acquired cells with the CellQuest software on a FACSCalibur system (BD Biosciences). For apoptosis detection, cells were first stained with allophycocyanin anti-CD8, washed, and then treated with FITC-annexin V (BD Biosciences) for $20 \mathrm{~min}$ at room temperature, according to the manufacturer; 7-AAD (eBioscience) was added just before flow cytometry. For analysis, we used the FlowJow software (TreeStar, Ashland, OR, USA).

Microscopy. Upon cytospining, PECs were fixed in a glass layer with $4 \%$ paraformaldehyde, followed by staining with Alexa Fluor 488-labeled anti-MGL1, PE-labeled anti-CD8, and DAPI (4',6-diamidino-2-phenylindole, dihydrochloride; Invitrogen Life Technologies, Carlsbad, CA, USA) for nuclear staining. For immunofluorescence, images were captured with an Imager M2 ApoTome microscope (Zeiss, Oberkochen, Germany) or with an EVOS fl $_{\text {(AMG - Advanced }}$ Microscopy Group, Bothell, WA, USA). For optical microscopy, PECs from infected mice were stained with the Panoptic Staining Kit (Laborclin, Pinhais, Brazil). The images were acquired with an Olympus BX51 microscope (Olympus Optical Co., Tokyo, Japan) and an Olympus 72 digital camera (Olympus Optical Co.).

Peritoneal exudates and cell cultures. PECs were collected in $3-5 \mathrm{ml}$ of DMEM (Invitrogen Life Technologies), supplemented with $2 \mathrm{mM}$ glutamine, $5 \times 10^{5}$ M 2-ME, $10 \mu \mathrm{g} / \mathrm{ml}$ gentamicin, $1 \mathrm{mM}$ sodium pyruvate, and $0.1 \mathrm{mM} \mathrm{MEM}$ nonessential amino acids (culture medium). Upon centrifugation, supernatants were collected for cytokine assays. PECs were processed for flow cytometry and cultures. PECs ( 1 or $1.5 \times 10^{6}$ cells) were added to 24 -well vessels and maintained in culture medium plus 10\% FCS (Invitrogen Life Technologies) during 2-3 h and then gently washed to remove the excess of non-adherent cells, but retain CD8 T cells (30-40\% of cells recovered from $24 \mathrm{~h}$ supernatants washed from cultures). Other non-adherent PECs are about $14-20 \%$ of B cells, $5-7 \%$ CD4 T cells, $1-2 \%$ $\mathrm{CD}_{11 \mathrm{c}^{+} \text {, and } 1-4 \% \text { Ly6G }}{ }^{+}$cells. Cultures enriched in T cells $(70-80 \%$ CD8 T cells recovered from culture supernatants) were obtained by culturing PECs on platebound anti-CD8 (53-6.7) mAb or anti-CD3 (145-2C11) mAb $(10 \mu \mathrm{g} / \mathrm{ml}$; BD Biosciences) during $2 \mathrm{~h}$ before washing out non-adherent cells. The remaining cells were maintained in culture medium plus $10 \% \mathrm{FCS}$ at $37^{\circ} \mathrm{C}$ and $7 \% \mathrm{CO}_{2}$ in a humid atmosphere. Some cultures also received $\mathrm{T}$. cruzi Ag (lysates of $1 \times 10^{6}$ metacyclic parasites per well). These mixed cultures were treated or not with $10 \mu \mathrm{g} / \mathrm{ml}$ of antiFasL (MFL3) mAb or control IgG mAb (eBioscience), or with $40 \mu \mathrm{M}$ of $\mathrm{ZVAD}$ (BD Biosciences) or $0.2 \%$ DMSO (Sigma, St Louis, MO, USA). After $48 \mathrm{~h}$, we collected supernatants for cytokine assays or mixed supernatants with equal volumes of the Griess reagent ( $1 \%$ sulfanilamide, $0.1 \%$ naphthylethylenediamine dihydrochloride, $2 \% \mathrm{H}_{3} \mathrm{PO}_{4}$; Sigma) to determine $\mathrm{NO}$ production. The absorbance was measured at $540 \mathrm{~nm}$ and results are expressed as the content of nitrites, based on the concentration of sodium nitrite solutions as standard. After washing out non-adherent cells, macrophages were evaluated for viability by MTT (3-(4,5-dimethylthiazol-2-yl)-2,5-diphenyltetrazolium bromide from Sigma) assay or detached with $2 \mathrm{mM}$ EDTA (plus $2 \% \mathrm{FCS}$ ) at $4{ }^{\circ} \mathrm{C}$ and processed for flow cytometry, as above.

Infected macrophages. PECs $\left(5 \times 10^{5}\right.$ or $1 \times 10^{6}$ cells per well) were cultured in 48-well vessels during $2-3 \mathrm{~h}$ and then washed for removal of nonadherent cells. Macrophages were infected or not with $T$. cruzi parasites $\left(1 \times 10^{6}\right.$ metacyclic parasites per well) during $3-4 \mathrm{~h}$ before washing out extracellular parasites and additional non-adherent cells. Cultures were maintained in culture medium plus $10 \% \mathrm{FCS}$ at $37{ }^{\circ} \mathrm{C}$ and $7 \% \mathrm{CO}_{2}$ in a humid atmosphere. Trypomastigotes released from macrophages were counted in culture supernatants after 2-4 weeks of infection.

T cells. Splenocytes were depleted of red blood cells by treatment with Tris-buffered ammonium chloride, followed by nylon wool filtration to obtain T-cellenriched suspensions. Purified CD8 T cells were obtained by negative selection of T-cell-enriched suspensions with a mAb mix (containing anti-B220, anti-panNK, antiMHC-II, anti-CD4, and anti-CD11b mAbs from BD Biosciences) and anti-rat IgG magnetic beads (Dynal, Oslo, Norway). Purified suspensions contained $85-95 \%$ $\mathrm{CD}^{+}$cells, as stained for detection of residual CD4 T cells and B cells with antiCD19, anti-CD5, and anti-CD8 mAbs. In Figures $4 a$ and b, we used 98\% pure CD8 $\mathrm{T}$ cells positively selected by cell sorting with allophycocyanin- and PE-labeled anti-CD8 mAbs (53-6.7, eBioscience); by excluding CD4 ${ }^{+}$cells marked with FITC-labeled anti-CD4 mAb (GK1.5; BD Bioscience) in a MoFlo cytometer (Cytomation, Ft Collins, CO, USA).

Macrophages cocultured with CD8 T cells. Purified CD8 T cells $\left(1 \times 10^{6}\right.$ cells or $2 \times 10^{6}$ cells per well) were added to infected macrophages $\left(5 \times 10^{5}\right.$ or $1 \times 10^{6}$ cells per well) in 48-well vessels and maintained in culture medium plus $10 \%$ FCS $\left(0.5 \mathrm{ml}\right.$ per well). Some cocultures were set with CD8 T cells $\left(3 \times 10^{6}\right)$ well) and non-infected macrophages $\left(1.5 \times 10^{6} /\right.$ well) in 24-well vessels. Cocultures were treated with $1 \mathrm{ng} / \mathrm{ml} \mathrm{IL-2} \mathrm{(BD} \mathrm{Biosciences)} \mathrm{to} \mathrm{prevent} \mathrm{spontaneous} \mathrm{death}{ }^{22}$ and incubated with soluble anti-CD3 $(5 \mu \mathrm{g} / \mathrm{ml})$. Cocultures were then treated or not with anti-FasL (10 $\mu \mathrm{g} / \mathrm{ml})$ or control lgG mAb and maintained at $37^{\circ} \mathrm{C}$ and $7 \% \mathrm{CO}_{2}$ humid atmosphere during $48 \mathrm{~h}$. Supernatants were collected for NO and cytokine assays. Lymphocytes were processed for apoptosis assays. Trypomastigotes released from infected macrophages were counted in culture supernatants after 2-4 weeks of infection.

Treatment with anti-FasL. For in vivo inhibition of apoptosis, infected mice were injected intraperitoneally with $100 \mu \mathrm{g}$ of anti-FasL (MFL3 clone) mAb or control hamster IgG mAb (eBioscience) at 18 dpi. After 3 days, PECs were recovered with $4 \mathrm{ml}$ of culture medium and centrifuged. Supernatants were kept for cytokine assays and PECs were processed for flow cytometry or cultured in 48-well vessels and infected or not with metacyclic trypomastigotes, as described above.

Adoptive transfer of T cells. T-cell suspensions $\left(5 \times 10^{6} / \mathrm{ml}\right)$ from normal and infected (20 dpi) mice were stimulated in vitro with plate-bound anti-CD3 
$(10 \mu \mathrm{g} / \mathrm{ml})$ in the presence of $\mathrm{ZVAD}(40 \mu \mathrm{M})$ or $0.2 \%$ DMSO (control vehicle) during 4 or $24 \mathrm{~h}$. After $4 \mathrm{~h}, T$ cells from infected mice were recovered from the plates, washed to remove zVAD or DMSO, and injected intraperitoneally $\left(2 \times 10^{6} / 0.4 \mathrm{ml}\right)$ in infected mice (20 dpi). T cells that remained in cultures during $24 \mathrm{~h}$ were assayed for apoptotic CD4 and CD8 T cells. After 2 days, PECs were recovered from mice with $3 \mathrm{ml}$ of DMEM. Upon centrifugation, supernatants were kept for cytokine assays and PECs were cultured in 48-well vessels and infected or not with metacyclic trypomastigotes, as described above. For flow cytometry, suspensions containing $1 \times 10^{6}$ PECs were treated with $50 \mathrm{ng} / \mathrm{ml}$ of phorbol myristate acetate (PMA) (Sigma), $1 \mu \mathrm{g} / \mathrm{ml}$ of ionomycin (Sigma), and $1 \mu \mathrm{g} / \mathrm{ml}$ brefeldin (Golgiplug; BD Biosciences) in propylene tubes during $3 \mathrm{~h}$ before staining.

Cytokine assays. Culture supernatants or diluted peritoneal exudates were used for cytokine and chemokine assays by sandwich ELISA, by using pairs of specific mAbs (R\&D Systems or eBioscience), one of which was labeled with biotin, and developed with streptavidin-alkaline phosphatase (Invitrogen Life Technologies) and with $p$-nitrophenyl phosphate (Thermo Scientific Pierce, Waltham, MA, USA) as substrate. Cytokine levels were also analyzed in fresh supernatants by chemiluminescence arrays (Proteome Profiler - Mouse Cytokine Array Panel A Array Kit, R\&D Systems), according to the manufacturer's instructions.

Statistics. All tests were performed, by using the GraphPad Prism (v. 6.0) Results are expressed as average and S.E.M. in figures. The number ( $M$ ) of animals per group is indicated in figure legends. For parasite load, data were transformed to log of parasites per ml for statistical analysis. Data were analyzed by KolmogorovSmirnov test for assessing normal distribution and by unpaired Student's two-tailed t-test or ANOVA, followed by Dunnett's or Tukey's post-test. Significant differences are indicated for $\left.P<0.05\left(^{\star}\right), P<0.01\left(^{* \star}\right), P<0.0011^{(* *}\right)$, and $\left.P<0.0001{ }^{(* * *}\right)$. For in vitro experiments, data are expressed as the average of technical replicates per treatment and S.E.M. When analyzing more than two groups or treatments, we performed ANOVA followed by Tukey's or Bonferroni post-test. Significant differences in t-tests and ANOVA are indicated as above.

\section{Conflict of Interest}

The authors declare no conflict of interest.

Acknowledgements. We thank Hellen JV Beiral, Ricardo Schaffel, and Jorgete L Oliveira (UFRJ) for technical assistance. We thank Maurício M Rodrigues, in memoriam, for helpful discussions and for the gift of a peptide Ag. This work was supported by the Brazilian National Research Council (Conselho Nacional de Desenvolvimento Científico e Tecnológico, CNPq), the Rio de Janeiro State Science Foundation (Fundação Carlos Chagas Filho de Amparo à Pesquisa do Estado do Rio de Janeiro, FAPERJ), and the National Institutes of Science and Technology (INCT-INPeTAm/CNPq/MCT). MFL and GADR are research fellows at CNPq, Brazil.

1. Coura JR, Vinas PA. Chagas disease: a new worldwide challenge. Nature 2010; 465: S6-S7.

2. Lescure FX, Le Loup G, Freilij H, Develoux M, Paris L, Brutus L et al. Chagas disease: changes in knowledge and management. Lancet Infect Dis 2010; 10: 556-570.

3. Morillo CA, Marin-Neto JA, Avezum A, Sosa-Estani S, Rassi A Jr., Rosas F et al. Randomized Trial of benznidazole for chronic chagas' cardiomyopathy. N Engl J Med 2015; 373: 1295-1306.

4. Junqueira C, Caetano B, Bartholomeu DC, Melo MB, Ropert C, Rodrigues MM et al. The endless race between Trypanosoma cruzi and host immunity: lessons for and beyond Chagas disease. Expert Rev Mol Med 2010; 12: e29.

5. Aliberti JC, Cardoso MA, Martins GA, Gazzinelli RT, Vieira LQ, Silva JS. Interleukin-12 mediates resistance to Trypanosoma cruzi in mice and is produced by murine macrophages in response to live trypomastigotes. Infect Immun 1996; 64: 1961-1967.

6. Bafica A, Santiago HC, Goldszmid R, Ropert C, Gazzinelli RT, Sher A. Cutting edge: TLR9 and TLR2 signaling together account for MyD88-dependent control of parasitemia in Trypanosoma cruzi infection. J Immunol 2006; 177: 3515-3519.

7. Rodrigues MM, Oliveira AC, Bellio M. The immune response to Trypanosoma cruzi: role of Toll-like receptors and perspectives for vaccine development. J Parasitol Res 2012; 2012: 507874

8. Pellegrini A, Guinazu N, Giordanengo L, Cano RC, Gea S. The role of Toll-like receptors and adaptive immunity in the development of protective or pathological immune response triggered by the Trypanosoma cruzi protozoan. Fut Microbiol 2011; 6: 1521-1533.

9. Mills CD, Kincaid K, Alt JM, Heilman MJ, Hill AM. M-1/M-2 macrophages and the Th1/Th2 paradigm. J Immunol 2000; 164: 6166-6173.
10. Bastos KR, Alvarez JM, Marinho CR, Rizzo LV, Lima MR. Macrophages from IL-12p40deficient mice have a bias toward the M2 activation profile. J Leukoc Biol 2002; 71: 271-278.

11. Mantovani A, Sozzani S, Locati M, Allavena P, Sica A. Macrophage polarization: tumorassociated macrophages as a paradigm for polarized M2 mononuclear phagocytes. Trends Immunol 2002; 23: 549-555.

12. Murray PJ, Allen JE, Biswas SK, Fisher EA, Gilroy DW, Goerdt S et al. Macrophage activation and polarization: nomenclature and experimental guidelines. Immunity 2014; 41: 14-20.

13. Tarleton RL, Koller BH, Latour A, Postan M. Susceptibility of b2-microglobulin-deficient mice to Trypanosoma cruzi infection. Nature 1992; 356: 338-340.

14. Rottenberg ME, Bakhiet M, Olsson T, Kristensson $\mathrm{K}$, Mak T, Wigzell $\mathrm{H}$ et al. Differential susceptibilities of mice genomically deleted of CD4 and CD8 to infections with Trypanosoma cruzi or Trypanosoma brucei. Infect Immun 1993; 61: 5129-5133.

15. Kumar S, Tarleton RL. The relative contribution of antibody production and CD8+ T cell function to immune control of Trypanosoma cruzi. Parasite Immunol 1998; 20: 207-216.

16. Nickell SP, Stryker GA, Arevalo C. Isolation from Trypanosoma cruzi-infected mice of CD8+, MHC-restricted cytotoxic T cells that lyse parasite-infected target cells. J Immunol 1993; 150 1446-1457.

17. Nickell SP, Sharma D. Trypanosoma cruzi: roles for perforin-dependent and perforinindependent immune mechanisms in acute resistance. Exp Parasitol 2000; 94: 207-216.

18. Silverio JC, Pereira IR, Cipitelli Mda C, Vinagre NF, Rodrigues MM, Gazzinelli RT et al. $\mathrm{CD} 8+\mathrm{T}$-cells expressing interferon gamma or perforin play antagonistic roles in heart injury in experimental Trypanosoma cruzi-elicited cardiomyopathy. PLoS Pathog 2012; 8: e1002645.

19. Albareda MC, Laucella SA, Alvarez MG, Armenti AH, Bertochi G, Tarleton RL et al Trypanosoma cruzi modulates the profile of memory CD8+ T cells in chronic Chagas disease patients. Int Immunol 2006; 18: 465-471.

20. Lopes MF, Guillermo LV, Silva EM. Decoding caspase signaling in host immunity to the protozoan Trypanosoma cruzi. Trends Immunol 2007; 28: 366-372.

21. DosReis GA, Ribeiro-Gomes FL, Guillermo LV, Lopes MF. Cross-talk between apoptosis and cytokines in the regulation of parasitic infection. Cytokine Growth Factor Rev 2007; 18: 97-105.

22. Lopes MF, da Veiga VF, Santos AR, Fonseca ME, DosReis GA. Activation-induced CD4+ T cell death by apoptosis in experimental Chagas' disease. J Immunol 1995; 154: 744-752.

23. Lopes MF, Nunes MP, Henriques-Pons A, Giese N, Morse HC III, Davidson WF et al. Increased susceptibility of Fas ligand-deficient gld mice to Trypanosoma cruzi infection due to a Th2-biased host immune response. Eur J Immunol 1999; 29: 81-89.

24. Zuniga E, Motran C, Montes CL, Diaz FL, Bocco JL, Gruppi A. Trypanosoma cruzi-induced immunosuppression: B cells undergo spontaneous apoptosis and lipopolysaccharide (LPS) arrests their proliferation during acute infection. Clin Exp Immunol 2000; 119: 507-515.

25. Nunes MP, Andrade RM, Lopes MF, DosReis GA. Activation-induced T cell death exacerbates Trypanosoma cruzi replication in macrophages cocultured with CD4+ T lymphocytes from infected hosts. J Immunol 1998; 160: 1313-1319.

26. Guillermo LV, Silva EM, Ribeiro-Gomes FL, De Meis J, Pereira WF, Yagita $\mathrm{H}$ et al. The Fas death pathway controls coordinated expansions of type 1 CD8 and type 2 CD4 T cells in Trypanosoma cruzi infection. J Leukoc Biol 2007; 81: 942-951.

27. Vasconcelos JR, Bruna-Romero O, Araujo AF, Dominguez MR, Ersching J, de Alencar BC et al. Pathogen-induced proapoptotic phenotype and high CD95 (Fas) expression accompany a suboptimal CD8+ T-cell response: reversal by adenoviral vaccine. PLoS Pathog 2012; 8: e1002699.

28. Freire-de-Lima CG, Nascimento DO, Soares MB, Bozza PT, Castro-Faria-Neto HC de Mello FG et al. Uptake of apoptotic cells drives the growth of a pathogenic trypanosome in macrophages. Nature 2000; 403: 199-203.

29. Silva EM, Guillermo LV, Ribeiro-Gomes FL, De Meis J, Nunes MP, Senra JF et al. Caspase inhibition reduces lymphocyte apoptosis and improves host immune responses to Trypanosoma cruzi infection. Eur J Immunol 2007; 37: 738-746.

30. Guillermo LV, Pereira WF, De Meis J, Ribeiro-Gomes FL, Silva EM, Kroll-Palhares K et al. Targeting caspases in intracellular protozoan infections. Immunopharmacol Immunotoxicol 2009; 31: 159-173.

31. Poon IK, Lucas CD, Rossi AG, Ravichandran KS. Apoptotic cell clearance: basic biology and therapeutic potential. Nat Rev Immunol 2014; 14: 166-180.

32. Silva EM, Guillermo LV, Ribeiro-Gomes FL, De Meis J, Pereira RM, Wu Z et al. Caspase-8 activity prevents type 2 cytokine responses and is required for protective $T$ cell-mediated immunity against Trypanosoma cruzi infection. J Immunol 2005; 174: 6314-6321.

33. Lopes MF, Cunha JM, Bezerra FL, Gonzalez MS, Gomes JE, Lapa e Silva JR et al. Trypanosoma cruzi: both chemically induced and triatomine-derived metacyclic trypomastigotes cause the same immunological disturbances in the infected mammalian host. Exp Parasitol 1995; 80: 194-204.

34. Fonseca SG, Reis MM, Coelho V, Nogueira LG, Monteiro SM, Mairena EC et al. Locally produced survival cytokines IL-15 and IL-7 may be associated to the predominance of CD8+ T cells at heart lesions of human chronic Chagas disease cardiomyopathy. Scand J Immunol 2007; 66: 362-371.

35. Tzelepis F, de Alencar BC, Penido ML, Claser C, Machado AV, Bruna-Romero $O$ et al. Infection with Trypanosoma cruzi restricts the repertoire of parasite-specific CD8+ T cells leading to immunodominance. J Immunol 2008; 180: 1737-1748. 
36. Raes G, Brys L, Dahal BK, Brandt J, Grooten J, Brombacher F et al. Macrophage galactosetype C-type lectins as novel markers for alternatively activated macrophages elicited by parasitic infections and allergic airway inflammation. J Leukoc Biol 2005; 77: 321-327.

37. Cuervo H, Guerrero NA, Carbajosa S, Beschin A, De Baetselier P, Girones N et al. Myeloidderived suppressor cells infiltrate the heart in acute Trypanosoma cruzi infection. J Immunol 2011; 187: 2656-2665.

38. Silva GK, Costa RS, Silveira TN, Caetano BC, Horta CV, Gutierrez FR et al. Apoptosisassociated speck-like protein containing a caspase recruitment domain inflammasomes mediate IL-1beta response and host resistance to Trypanosoma cruzi infection. $J$ Immunol 2013; 191: 3373-3383.

39. Kuroda E, Noguchi J, Doi T, Uematsu S, Akira S, Yamashita U. IL-3 is an important differentiation factor for the development of prostaglandin E2-producing macrophages between C57BL/6 and BALB/c mice. Eur J Immunol 2007; 37: 2185-2195.

40. Munder M, Eichmann K, Modolell M. Alternative metabolic states in murine macrophages reflected by the nitric oxide synthase/arginase balance: competitive regulation by $\mathrm{CD} 4+$ T cells correlates with Th1/Th2 phenotype. J Immunol 1998; 160: 5347-5354.

41. Jenkins MR, Rudd-Schmidt JA, Lopez JA, Ramsbottom KM, Mannering SI, Andrews DM et al. Failed CTL/NK cell killing and cytokine hypersecretion are directly linked through prolonged synapse time. J Exp Med 2015; 212: 307-317.

42. A-Gonzalez N, Bensinger SJ, Hong C, Beceiro S, Bradley MN, Zelcer N et al. Apoptotic cells promote their own clearance and immune tolerance through activation of the nuclear receptor LXR. Immunity 2009; 31: 245-258.

43. Li F, Huang Q, Chen J, Peng Y, Roop DR, Bedford JS et al. Apoptotic cells activate the 'phoenix rising' pathway to promote wound healing and tissue regeneration. Sci Signal 2010; 3: ra13.

44. Chakour R, Allenbach C, Desgranges F, Charmoy M, Mauel J, Garcia I et al. A new function of the Fas-FasL pathway in macrophage activation. J Leukoc Biol 2009; 86: 81-90.

45. Conceicao-Silva F, Hahne M, Schroter M, Louis J, Tschopp J. The resolution of lesions induced by Leishmania major in mice requires a functional Fas (APO-1, CD95) pathway of cytotoxicity. Eur J Immunol 1998; 28: 237-245.

46. Ribeiro-Gomes FL, Otero AC, Gomes NA, Moniz-De-Souza MC, Cysne-Finkelstein L, Arnholdt AC et al. Macrophage interactions with neutrophils regulate Leishmania major infection. J Immunol 2004; 172: 4454-4462.

47. Hotchkiss RS, Chang KC, Swanson PE, Tinsley KW, Hui JJ, Klender P et al. Caspase inhibitors improve survival in sepsis: a critical role of the lymphocyte. Nat Immunol 2000; 1: 496-501.

48. Medeiros Al, Serezani CH, Lee SP, Peters-Golden M. Efferocytosis impairs pulmonary macrophage and lung antibacterial function via PGE2/EP2 signaling. J Exp Med 2009; 206: $61-68$.
49. Benoit M, Ghigo E, Capo C, Raoult D, Mege JL. The uptake of apoptotic cells drives Coxiella burnetii replication and macrophage polarization: a model for $Q$ fever endocarditis. PLoS Pathog 2008; 4: e1000066.

50. de Oliveira Fulco T, Andrade PR, de Mattos Barbosa MG, Pinto TG, Ferreira PF, Ferreira H et al. Effect of apoptotic cell recognition on macrophage polarization and mycobacterial persistence. Infect Immun 2014; 82: 3968-3978.

51. Lima RG, Moreira L, Paes-Leme J, Barreto-de-Souza V, Castro-Faria-Neto HC, Bozza PT et al. Interaction of macrophages with apoptotic cells enhances HIV Type 1 replication through PGE2, PAF, and vitronectin receptor. AIDS Res Hum Retrov 2006; 22: 763-769.

52. Ribeiro-Gomes FL, Peters NC, Debrabant A, Sacks DL. Efficient capture of infected neutrophils by dendritic cells in the skin inhibits the early anti-leishmania response. PLOS Pathog 2012; 8: e1002536.

53. Ribeiro-Gomes FL, Romano A, Lee S, Roffe E, Peters NC, Debrabant A et al. Apoptotic cell clearance of Leishmania major-infected neutrophils by dendritic cells inhibits CD8(+) T-cell priming in vitro by Mer tyrosine kinase-dependent signaling. Cell Death Dis 2015; 6: e2018.

54. Martin CJ, Booty MG, Rosebrock TR, Nunes-Alves C, Desjardins DM, Keren I et al. Efferocytosis is an innate antibacterial mechanism. Cell Host Microbe 2012; 12: 289-300.

55. Zagorska A, Traves PG, Lew ED, Dransfield I, Lemke G. Diversification of TAM receptor tyrosine kinase function. Nat Immunol 2014; 15: 920-928.

56. Mylonas KJ, Jenkins SJ, Castellan RF, Ruckerl D, McGregor K, Phythian-Adams AT et al. The adult murine heart has a sparse, phagocytically active macrophage population that expands through monocyte recruitment and adopts an 'M2' phenotype in response to Th2 immunologic challenge. Immunobiology 2015; 220: 924-933.

(c) (1) Cell Death and Disease is an open-access journal published by Nature Publishing Group. This work is licensed under a Creative Commons Attribution 4.0 International License. The images or other third party material in this article are included in the article's Creative Commons license, unless indicated otherwise in the credit line; if the material is not included under the Creative Commons license, users will need to obtain permission from the license holder to reproduce the material. To view a copy of this license, visit http://creativecommons.org/licenses/by/4.0/ 